\title{
Protective Effect of Preparations Containing Brassinosteroids on Plants Exposed to Environmental Lead Contamination: a Review
}

\author{
Natalya I. Grabovskaya and Olga N. Babenko* \\ Sh. Ualikhanov Kokshetau State University \\ Kokshetau, Republic of Kazakhstan
}

Received 18.04.2019, received in revised form 10.03.2020, accepted 13.05.2020, published online 27.05.2020

\begin{abstract}
The review article addresses the potential use of brassinosteroids and synthetic brassinosteroid-based preparations to protect plants exposed to environmental lead contamination. Under climate change and anthropogenic chemical pollution of the biosphere, this stressor is one of the most important agents that reduce the yield and quality of crops, and, therefore, it deserves close attention. Brassinosteroids and brassinosteroid-based preparations are regarded as universal plant growth stimulants and adaptogens. To support this assertion, it is important to study behavior of brassinosteroids under environmental lead contamination and discuss arguments in favor of their preferential use. The article provides information about the history of discovery and study of brassinosteroids, reports data on their chemical nature, biosynthesis, metabolism, and mechanisms of action on the plant cell, and describes interactions of brassinosteroids with other substances that stimulate plant growth and development. The article discusses phytotoxicity of lead and its influence on the growth, development, productivity, and resistance of plants. Literature data and results obtained by the authors provide evidence of the protective effect of brassinosteroids and brassinosteroid-based preparations on plants exposed to lead contamination and suggest reasons for their preferential use in the context of chemical pollution. Arguments are offered in favor of further research of these biostimulants in order to specify their use depending on the characteristics of the stress factor and biological properties of the plant.
\end{abstract}

Keywords: biostimulant, brassinosteroids, environmental pollution, heavy metals, lead, stress factor, Epin-Extra.

(C) Siberian Federal University. All rights reserved

This work is licensed under a Creative Commons Attribution-NonCommercial 4.0 International License (CC BY-NC 4.0).

* Corresponding author E-mail address: Babenko_ON@mail.ru

ORCID: 0000-0001-7826-1161 (Grabovskaya N.); 0000-0003-4114-1953 (Babenko O.) 


\title{
Протекторное действие на растения препаратов, содержащих брассиностероиды, в условиях загрязнения среды свинцом (обзор)
}

\author{
Н.И. Грабовская, О.Н. Бабенко \\ Кокшетауский государственный университет \\ им. Ш. Уалиханова \\ Республика Казахстан, Кокшетау
}

\begin{abstract}
Аннотация. В обзорной статье освещены вопросы, касающиеся возможности применения брассиностероидов и синтетических препаратов на их основе для защиты растений при загрязнении окружающей среды свинцом. В условиях изменения климата и антропогенного химического загрязнения биосферы данный стрессор является одним из важнейших агентов, снижающих урожайность и качество растениеводческой продукции, и поэтому он заслуживает пристального внимания. Брассиностероиды и препараты на их основе позиционируются как универсальные стимуляторы роста и адаптогены растений, поэтому для подтверждения данного тезиса важно рассмотреть особенности их действия в условиях воздействия названного выше стрессорного фактора с указанием аргументов в пользу их приоритетного использования. В статье приведена информация об истории открытия и изучения брассиностероидов, их химической природе, биосинтезе и метаболизме, механизмах действия на растительную клетку и возникающих при этом физиологических эффектах, а также особенностях взаимодействия брассиностероидов с другими стимулирующими рост и развитие растений веществами. Рассмотрены вопросы фитотоксичности свинца, его влияния на рост, развитие, продуктивность и устойчивость растений. На основе анализа литературных источников и собственных исследований приводятся доказательства протектирующего действия брассиностероидов и препаратов на их основе на растения в условиях свинцового загрязнения среды, аргументируются причины их приоритетного использования в условиях химического загрязнения. Приводятся аргументы в пользу дальнейшего изучения данных биостимуляторов с целью спецификации регламента применения в зависимости от особенностей стрессорного фактора и биологической природы растения.
\end{abstract}

Ключевые слова: биостимулятор, брассиностероиды, загрязнение окружающей среды, тяжелые металлы, свинец, стрессорный фактор, Эпин-Экстра.

Цитирование: Грабовская, Н.И. Протекторное действие на растения препаратов, содержащих брассиностероиды, в условиях загрязнения среды свинцом (обзор) / Н.И. Грабовская, О.Н. Бабенко // Журн. Сиб. федер. ун-та. Биология, 2020. 13(2). C. 129-163. DOI: 10.17516/1997-1389-0322 


\section{Введение}

Рынок всевозможных биостимуляторов является одним из самых быстрорастущих секторов сельского хозяйства. В настоящее время активно изучаются вопросы, касающиеся биологических свойств брассиностероидов (БС), совершенствуются технологии их синтеза и выделения природных соединений, разрабатываются на их основе новые препараты для применения в растениеводстве (Яхин и др., 2014). Препараты на основе БС обладают широким спектром стимулирующего и защитного действия, что приводит к увеличению урожайности и повышению качества сельскохозяйственной продукции. Они эффективные иммуномодуляторы, увеличивают устойчивость растений к стрессу, фитопатогенам, болезням, регулируют рост и развитие растений, улучшают бутоно- и плодообразование, способствуют обильному цветению. Данные препараты рекомендуются для обработки различных сельскохозяйственных культур (зерновые, бобовые, картофель и овощи, сахарная свекла, лен, хлопок), а также для применения в декоративном садоводстве, ландшафтном дизайне и городском озеленении. Однако следует отметить, что как в инструкциях по применению препаратов на основе БС, так и в литературных источниках (Bajguz, Hayat, 2009; Allagulova et al., 2015; Sharma et al., 2016a; Sharma et al., 2016b; He et al., 2016; Rao, Raghu, 2017; Kohli et al., 2018; Wang et al., 2018; Planas-Riverola et al., 2019; Surgun-Acar, Zemheri-Navruz, 2019; Wu et al., 2019) отсутствует информация об эффективности и целесообразности применения БС, производным которых является биостимулятор Эпин-Экстра, в условиях загрязнения среды тяжелыми металлами (ТМ), в частности свинцом $(\mathrm{Pb})$. Данный аспект требует дополнительного изучения, так как количество $\mathrm{Pb}$ в окружающей среде стабильно увеличи- вается. Известно, что высокие концентрации $\mathrm{Pb}$ в почвах в значительной степени могут подавлять рост и развитие растений (Алексеев, 2008), что в свою очередь ведет как к снижению их продуктивности и устойчивости, так и к загрязнению ТМ продуктивных органов, используемых в пищевых и кормовых целях (Гармаш, 1983). Синтетические адаптогены растений на основе естественных фитогормонов, к которым относится Эпин-Экстра, физиологичны и безопасны для окружающей среды и способны в некоторой степени нивелировать вредное воздействие данного фактора. Поэтому при использовании регуляторов роста растений на основе фитогормонов нужно учитывать не только их способность увеличивать урожайность, но и способность влиять на безопасность растениеводческой продукции, в частности снижать кумуляцию $\mathrm{Pb}$ в продуктивных органах растений. В связи с этим представляется целесообразным изучение действия биостимуляторов, содержащих БС, на растения в условиях свинцового загрязнения окружающей среды.

\section{Эпин-Экстра как биостимулятор роста и антистрессовый адаптоген}

Эпин-Экстра - зарегистрированный товарный знак Автономной некоммерческой организации «НЭСТ М» (www.nest-m.ru) и название препарата, содержащего в качестве действующего вещества (в концентрации 0,025 г/л) высокоочищенный 24-эпибрассинолид (рис. 1), относящийся к классу БС и синтезированный по оригинальной методике с использованием нанотехнологий (Патент РФ № 2272044 от 13.09 .04 «Способ получения 24-эпибрассинолида», свидетельство о государственной регистрации № 1771 от 26.02.18 взамен ранее выданного свидетельства о государственной регистрации № 1119 от 20 мая 2016 г.). 


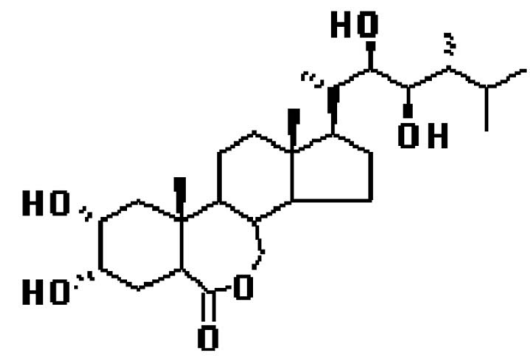

Рис. 1. Структурная формула 24-эпибрассинолида

Fig. 1. Structural formula of 24-epibrassinolide

На сегодняшний день Эпин-Экстра широко используется за рубежом в условиях проблемного земледелия, особенно в Японии (Ikekawa, Zhao, 1991; Sakurai et al., 1999; Toyama, 2000; Yamagami et al., 2018), Индии (Sharma et al., 2015; Sharma et al., 2016a; Sharma et al., 2016b; Sharma et al., 2019) и Китае (He et al., 2016; Zheng et al., 2017; Cai et al., 2019; Yin et al., 2019). Являясь синтетическим аналогом натурального фитогормона, он не опасен для человека и окружающей среды (IV класс опасности), не загрязняет почву, грунтовые и поверхностные воды, безопасен для рыб, пчел и других полезных насекомых. Имеются сведения, что данный регулятор роста даже стимулирует жизнедеятельность почвенных микроорганизмов, способствуя улучшению минерального питания растений (Пономаренко, 1999).

БС $\left(\mathrm{C}_{28} \mathrm{H}_{18} \mathrm{O}_{6}\right)$ представляют собой класс стероидных гормонов, которые играют важную роль в регуляции роста и развития растений. Открыты они были сравнительно недавно (Khripach et al., 2000). Еще в 19301940-е гг. учеными было высказано предположение о том, что в растениях можно обнаружить стероидные регуляторы роста по аналогии со стероидными гормонами животных (Skarzynski, 1933; Hassan, Wafa, 1947). В многочисленных биотестах растения подвергали обработке стероидными гормонами жи- вотных, которые оказывали физиологическое действие (Love, Love, 1945). Например, эстрогены вызывали деление клеток в зародышах гороха (Kopcewicz, Rogozinska, 1972; Jones, Roddick, 1977), а с помощью тестостерона удалось изменить пол у растений бешеного огурца (Ecballium elaterium L.) (Kopcewicz, 1971) и сосны обыкновенной (Pinus silvestris L.) (Kopcewicz et al., 1977). Однако животные гормоны приходилось использовать в слишком высоких концентрациях (порядка 0,1%), и вряд ли можно было говорить о специфичности полученных результатов. И только в 1979 г. было окончательно подтверждено наличие стероидных гормонов в растениях, когда американские ученые опубликовали данные о новом стероидном соединении под названием брассинолид, который был выделен ими из пыльцы рапса (Brassica napus L.), собранной пчелами (Grove et al., 1979). Три года спустя кастастерон, биосинтетический предшественник брассинолида, был выделен из галлов насекомых на каштане японском (Castanea crenata Sieb. \& Zucc.) (Yokota et al., 1982). В настоящее время известно более 60 соединений с брассиностероидной активностью. Наибольшим содержанием этих веществ отличается пыльца растений, но БС были обнаружены также и в вегетативных органах, и в цветках (Fujioka et al., 1996; Toyama, 2000). Например, из настоящего каштана 
(Castanea sativa Mill.) был выделен кастастерон, обнаруженный также в незрелых семенах периллы фруктовой (Perilla frutescens (L.) Britt.) и риса (Oryzae sativa L.) (Park et al., 1994), из рогоза (Typha) - тифастерол (Schneider et al., 1983), из чая (Thea) - теастерон (Abe et al., 1984), и т.д. Недавно БС были также обнаружены у печеночного мха (Marchantia polymorpha L.), зеленого мха (Physcomitrella patens (Hedw.) Bruch \& Schimp.), плаунков (Selaginella moellendorffii Hieron. и S. uncinata (Desv. ex Poir.) Spring) и 13 видов папоротников (Yokota et al., 2017).

Биосинтез БС идет по мевалонатному пути (Муромцев и др., 1987; Fujioka, Sakurai, 1997; Clouse, Sasse, 1998) и включает общие для других терпеновых соединений (гиббереллины, абсцизовая кислота (АБК), фузикоксины, каротиноиды) стадии: синтез изопентенилпирофосфата $\left(\mathrm{C}_{5} \mathrm{H}_{12} \mathrm{P}_{2} \mathrm{O}_{7}\right)$, геранилпирофосфата $\left(\mathrm{C}_{10} \mathrm{H}_{20} \mathrm{P}_{2} \mathrm{O}_{7}\right)$, фарнезилпирофосфата $\left(\mathrm{C}_{15} \mathrm{H}_{28} \mathrm{P}_{2} \mathrm{O}_{7}\right)$, сквалена $\left(\mathrm{C}_{30} \mathrm{H}_{49} \mathrm{OH}\right)$. Первым специфическим продуктом, из которого происходит биосинтез остальных БС, является 24-метиленхолестерол, превращающийся в кампестерин и кампестанол. От кампестанола расходятся две параллельные ветви биосинтеза, часто одновременно сосуществующие в растительных клетках: с ранним и с поздним окислением в С-6-положении. В итоге обе ветви биосинтеза заканчиваются брассинолидом - физиологически активным БС (Кретович, 1986).

Многие из ферментов биосинтеза БС были выделены и охарактеризованы благодаря мутациям, приводящим к карликовости, восстанавливаемой брассинолидом. Так, у арабидопсиса (Arabidopsis thaliana (L.) Heynh.) мутации $d w f 1$ и $d w f 6$ (от dwarf - карлик) контролируют ранние этапы биосинтеза БС (до разделения на «ранний» и «поздний» путь биосинтеза) и обладают наиболее силь- ным фенотипическим проявлением - мутанты достигают не более чем 1/30 высоты растений дикого типа. Мутация $d w f 4$ затрагивает более поздние этапы биосинтеза БС (после развилки в метаболизме), поэтому фенотипическое проявление карликовости мягче (Choe et al., 1999; Noguchi et al., 2000).

БС - высокогидрофобные молекулы. Тем не менее при добавлении меченого брассинолида наблюдается его транспорт по побегу в акропетальном направлении. Зарегистрировано образование гидрофильных гликозидов, сульфатов и ацилпроизводных БС (Abe, 1989). Возможно, с образованием этих соединений и связан акропетальный транспорт брассинолида по растению. Хотя ферменты биосинтеза БС обнаружены почти во всех тканях растения, их концентрация наиболее высока в молодых тканях: этиолированных проростках, меристемах, флоральных примордиях, развивающейся пыльце (Abe, 1989; Bishop, Yokota, 2001). По-видимому, такое распределение БС вызвано процессами дальнего и ближнего транспорта. Однако некоторые авторы (Shimada et al., 2003) утверждают, что БС синтезируются в тканях, смежных с теми, где они функционируют. В своих исследованиях Г.М. Саймонс с соавторами (Symons, Reid, 2004) также не обнаружил доказательств переноса этих веществ на большие расстояния между различными тканями растения.

БС отличаются от ауксинов, цитокининов и этилена молекулярным строением и функциями (Davies, 2004). При действии БС на проростки они, как и ауксины, усиливают растяжение. Однако для ауксинов характерно быстрое растяжение, при котором активация $\mathrm{H}+$-помпы наблюдается через 10 мин с максимумом растяжения через 30-45 мин после воздействия, а для БС типична более замедленная реакция, которая начинается через 30 мин после воздействия и продолжается в 
течение 1,5-2 ч. Если при этом в среду для роста растений добавить БС совместно с ауксинами, то они окажут гораздо больший стимулирующий эффект, чем при действии только ауксинов или только БС (Tran, Pal, 2014). На молекулярном уровне эффект растяжения, по-видимому, обусловлен активацией генов ксилоглюканэндотрансгликозилаз (КсЭТ). Активация таких генов показана в разных растительных объектах. Это ген TCH 4 арабидопсиса (A. thaliana) (Campbell, Braam, 1998; Iliev et al., 2002), ген $B R U 1$ сои (Glycine max (L.) Merr.) (Oh et al., 1996; 1998), ген SlBRI 1 томатов (Zhu et al., 2019) и др. Белки КсЭТ после биосинтеза направляются в клеточную стенку и при взаимодействии с ксилоглюканами размягчают ее матрикс. Таким образом, если ауксины запускают процесс растяжения, то БС важны для его длительного поддержания.

Установлено, что БС регулируют процессы клеточной дифференцировки (Iwasaki, Shibaoka, 1991; Cano-Delgado et al., 2004; Yamamoto et al., 2007). Так, у мутантов арабидопсиса (A. thaliana) с подавленным ответом на брассиностероиды bri 1 нарушалось формирование столбчатого мезофилла и уменьшалось количество проводящих элементов ксилемы (Clouse et al., 1996; Cano-Delgado et al., 2004). Процесс дифференцировки ксилемных элементов, как и в случае растяжения, запускают ауксины. Причем в этом процессе можно выделить три стадии: 1) первичная экспрессия генов, приводящая к накоплению фенилаланин-аммикалиазы (ФАЛ) и гидроксилазы коричной кислоты (ГКК); 2) остановка экспрессии этих генов и переориентация актиновых филаментов; 3) вторичный запуск синтеза ФАЛ и ГКК с дальнейшей сильной лигнификацией и апоптозом - программированной гибелью клеток. Оказалось, что переход от стадии 2 к стадии 3 невозможен без БС. Таким образом, уже в двух случаях ауксины и БС выступают как синергисты. БС и ауксин проявляют некоторые сходные физиологические эффекты, вероятно, благодаря их функциональному взаимодействию, но точный механизм этого взаимодействия пока неизвестен.

В то же время действие на корневую систему БС и ауксинов заметно различается: если ауксины стимулируют образование боковых корней, то БС в большинстве случаев ингибируют их образование (Gonzalez-Garcia et al., 2011). Однако существуют и противоположные данные. Так, БС стимулировали рост и развитие корневой системы льна-долгунца (в 1,3 раза по сравнению с фоном), причем увеличение корневой массы происходило в основном за счет образования боковых корешков (Кукреш, Ходянкова, 2002). А исследования Ф. Бао с соавторами (Bao et al., 2004) показали, что БС действуют синергически с ауксином, способствуя образованию латеральных корней у арабидопсиса (A. thaliana) за счет увеличения акропетального переноса ауксина (от основания до кончика) в корне.

БС взаимодействуют не только с ауксинами, но и с гиббереллинами, усиливая растяжение клеток. При повреждении биосинтеза БС проростки заметно уменьшаются в длине (Abe, 1989; Yin et al., 2019). Установлено, что эпибрассинолид оказывает более сильный стимулирующий эффект на рост растяжением по сравнению с индолилуксусной (ИУК) и гибберелловой (ГК) кислотами (Xu et al., 1990; Bai et al., 2012). Кроме того, без БС растения не способны удерживать апикальную петельку в согнутом состоянии, семядоли преждевременно раскрываются и биосинтез хлорофилла идет в темноте (Bai et al., 2012). Все эти реакции не характерны для растений, выращенных без света. Поэтому в настоящее время активно обсуждается участие БС в передаче световых сигналов и перекрест путей 
фоторецепции и БС. Так, результаты, полученные С.Ю. Тищенко с соавторами (2001a, 2001b) при изучении влияния 24-эпибрассинолида на рост и гормональный баланс проростков арабидопсиса (A. thaliana), позволяют предположить регуляторную роль 24-эпибрассинолида в процессе фотоморфогенеза арабидопсиса на синем свету. Измерение уровня гормонов показало, что 24-эпибрассинолид увеличивал в 7-суточных проростках арабидопсиса содержание ИУК, цитокининов и особенно АБК (уровень которой был примерно в 3 раза выше, чем в контроле) и значительно уменьшал содержание связанных форм гиббереллинов группы ГК4,7 (Тищенко и др., 2001 a, b). В связи с этим можно предположить, что эпибрассинолид принимает участие в регуляции баланса эндогенных гормонов в растениях.

Некоторые исследования показывают, что БС и гиббереллины действуют независимо друг от друга, однако имеются данные о синергическом или аддитивном эффекте (Головацкая, Винникова, 2007). Так, в темноте у проростков арабидопсиса (A. thaliana) развивается апикальная петелька (структура, защищающая семядоли и апикальные меристематические ткани при прорастании через почву) за счет дифференциального удлинения и деления клеток на противоположных сторонах гипокотиля, где скорость удлинения клеток на внешней стороне больше, чем на внутренней (Silk, Erickson, 1978; Li et al., 2004). Было показано, что данный процесс управляется перекрестным взаимодействием между несколькими гормонами (De Grauwe et al., 2005; An et al., 2012). Известно, что ауксины, этилен и гиббереллины координированно взаимодействуют при образовании апикальной петельки (Achard et al., 2003; Li et al., 2004; Vriezen et al., 2004; De Grauwe et al., 2005; Zadnikova et al., 2010; Vandenbussche et al., 2010). Исследования Накамуры с соавторами (Nakamura et al., 2003) продемонстрировали также регуляцию брассинолидами нескольких генов ауксинового ответа при образовании апикальной петельки. Участие БС в формировании апикальной петельки подтверждается и тем, что нарушение синтеза БС изменяет реакцию ауксина предположительно путем воздействия на транспорт ауксина (De Grauwe et al., 2005).

На свету подобная сложная гормональная регуляция была обнаружена на уровне удлинения гипокотиля, стимулировать которое могут как ауксины, гиббереллины, этилен или его предшественник 1-аминоциклопропан-1карбоксильная кислота (АКК), так и БC (De Grauwe et al., 2005). Была предложена гипотеза о взаимодействии этилена с ауксинами (Smalle et al., 1997; Vandenbussche et al., 2003a), а также рассмотрена связь этилена и ауксинов с гиббереллинами (Saibo et al., 2003). Однако вопрос, где и как в этой сети гормональной регуляции вступают в игру БС, остается активно обсуждаемым.

Можно провести некоторые параллели между образованием апикальной петельки в темноте и удлинением гипокотиля на свету. Во-первых, оба процесса зависят от этилена и ауксина (Schwark, Schierle, 1992; Boerjan et al., 1996; Lehman et al., 1996; Smalle et al., 1997; Zhao et al., 2001; Vandenbussche et al., 2003a, 2003b; De Grauwe et al., 2005; Stepanova et al., 2008; An et al., 2012). Во-вторых, они оба имеют временное окно чувствительности (Raz, Ecker, 1999; Saibo et al., 2003). В-третьих, анализ hls мутантов арабидопсиса показывает, что их соответствующие генные продукты функционируют не только в этиленопосредованном образовании апикальной петельки в темноте, но и в этилен-стимулированном удлинении гипокотиля на свету (Vandenbussche et al., 2003a; De Grauwe et al., 
2005; An et al., 2012). Следовательно, эти реакции, по-видимому, контролируются одними и теми же механизмами. Необходимо отметить, что на свету БС способны компенсировать нечувствительность к этилену $h l s$ мутантов, что предполагает их существенную роль в данном процессе (De Grauwe et al., 2005).

В последнее время большое внимание уделяется изучению влияния БС на показатели продуктивности и урожайности сельскохозяйственных растений. Известно, что БС оказывают воздействие при более низких концентрациях $\left(10^{-13}-10^{-11} \mathrm{M}\right)$, чем остальные фитогормоны (Khripach et al., 2000). Наиболее простым и экономичным способом применения БС признано замачивание семян среднего размера в течение 6 ч в растворе гомобрассинолида $(0,05$ мг/л) с последующей подсушкой на воздухе перед посевом (Sairam, 1994). Установлена возможность его применения и путем опрыскивания, однако при этом больше расход препарата и, следовательно, выше общие денежные затраты.

Имеются многочисленные данные, что эпибрассинолиды стимулируют прорастание и всхожесть семян на 15-20 \% (Budaj, 2000; Елагина, Вьюгина, 2001; Miransari, Smith, 2014; Kim et al., 2019; Small et al., 2019), способствуют формированию боковых побегов (Pugachov et al., 2000; Small, Degenhardt, 2018), увеличению площади ассимиляционной поверхности листьев, продуцированию большей биомассы (Sairam, 1994), улучшению клубне- и плодообразования на 17-34 \% (Гайтер, 2001; Попова, 2001). У обработанных эпибрассинолидом растений также наблюдалось увеличение количества завязей плодов на $50 \%$, предотвращалось их опадание и ускорялись темпы образования и созревания плодов в среднем на $11 \%$ (Гайтер, 2001).

Положительное влияние эпибрассинолида на продуктивность сельскохозяйственных растений связывают с усилением дыхания, поглощения влаги и азота из почвы, что благоприятствует фотосинтезу, синтезу белков, активному росту и развитию растений и в конечном итоге формированию высокого урожая. Установлено, что применение БС увеличивает урожайность на 25-42 \% (Стрельцова, Ольховик, 1990; Sairam, 1994; Гайтер, 2001; Попова, 2001; Gomes et al., 2006; Hayat et al., 2012; Serna et al., 2012; Ali, 2017).

Нужно также отметить, что обработка посадочного материала раствором эпибрассинолида снижает содержание нитратов в продукции в 2-3 раза (Budaj, 2000; Попова, 2001) и увеличивает накопление крахмала, аскорбиновой кислоты и других органических соединений (Попова, 2001), тем самым повышая питательную ценность сельскохозяйственной продукции. Влияние эпибрассинолида на транспорт и накопление в растениях ценных метаболитов в настоящее время активно изучается сотрудниками Сибирского института физиологии и биохимии растений СО РАН (г. Иркутск) (Горбылева, Боровский, 2018; Glyan'ko, 2018). Транспорт через вакуолярную мембрану сахаров, аминокислот, а в некоторых случаях и неорганических ионов $\left(\mathrm{K}^{+}, \mathrm{Na}^{+}\right.$, $\left.\mathrm{Ca}^{2+}, \mathrm{NO}_{3}{ }^{-}, \mathrm{Cl}^{-}\right)$энергетически зависим. Полагают, что регуляция транспорта этих веществ может осуществляться через регуляцию активности $\mathrm{H}^{+}$-АТФазы (Е.С. 3.6.1.34) и $\mathrm{H}^{+}$пирофосфатазы (Е.C. 3.6.1.1) (Stevens, Forgas, 1997; Forgac, 1998). Исследования Е.В. Прадедовой (2001) показали, что эпибрассинолид может одновременно регулировать и гидролитическую, и транспортную функции $\mathrm{H}^{+}$АТФазы и $\mathrm{H}^{+}$-пирофосфатазы вакуолярной мембраны корнеплодов столовой свеклы, и эта регуляция зависит от стадии онтогенеза. Наряду с этим эпибрассинолид способен стимулировать поступление сахарозы только через активацию $\mathrm{H}^{+}$-АТФазы тонопласта (со- 
держание сахарозы увеличивалось на 40 \%), тогда как в присутствии пирофосфатазы эпибрассинолид не стимулировал поступление сахарозы в вакуоли (Озолина и др., 2007).

В инструкциях по использованию препарата Эпин-Экстра не рекомендуется при применении смешивать его с другими препаратами. Однако В.М. Гончарук с сотрудниками (2002) установила, что бинарные композиции 2'-5'-олигонуклеотидов и БС превосходили по своей биологической активности отдельно взятые компоненты. Причем урожай картофеля, полученный с применением указанных смесей, составил 179-242 \% к контролю в тепличных условиях и 154-183 \% - в полевых условиях, а комбинированные обработки семян ярового ячменя сорта Gonar смесями солей карбоксиметилцеллюлозы с 24-эпибрассинолидом, янтарной кислотой или экстрактом алкалоидов в полевых условиях привели к увеличению урожая на 0,26-0,39 т (Kabashnikova et al., 1998). Следовательно, вопрос о применении БС в комплексе с другими препаратами для обработок сельскохозяйственных культурных растений также нуждается в дальнейшем изучении, к тому же применение бинарных или других смесей позволит снизить нормы расхода составляющих их препаратов и сделать их перспективными для практического использования в качестве стимуляторов роста и развития растений.

В современной научной литературе имеются многочисленные данные о способности БС повышать толерантность растений к стрессовым воздействиям (Ali et al., 2007; Kagale et al., 2007; Ali et al., 2008; Bajguz, 2009; Bajguz, Hayat, 2009; Yuan et al., 2010; Hayat et al., 2012; Jiang et al., 2013; Fariduddin et al., 2014; Fang et al., 2019; Fu et al., 2019; Parmoon et al., 2019) и устойчивость к болезням (Abe, 1989; Елагина, Вьюгина, 2001; Кукреш, Ходянкова, 2002; Albrecht et al., 2012; Alazem, Lin, 2015; Deng et al., 2016). БС являются природными адаптогенами, запускающими в растительных клетках защитные механизмы при стрессовых воздействиях: засухах (Пустовойтова, 1990; Sairam, 1994; Бабенко, 2004; Бабенко, Сафронова, 2007; Сафронова, Бабенко, 2008; Yuan et al., 2010; Nie et al., 2019; Wang et al., 2019), 3aморозках (Pociecha et al., 2015; Filek et al., 2017; Janeczko et al., 2019), высоких температурах (Sonjaroon et al., 2018; Bhattacharya, 2019), недостаточной освещенности (Kang et al., 2001; $\mathrm{Li}, \mathrm{He}, 2016$ ), пересадке, черенковании (Small, Degenhardt, 2018; Zhou et al., 2018). В стрессовых условиях в клетках растения повышается активность ферментов, изменяется структура и функция мембран (Dahse et al., 1990; Прадедова, 2001), ускоряется клеточное деление (Pugachov et al., 2000; Зубарев, 2001; Small, Degenhardt, 2018), синтезируется «шоковый» белок (Кулаева и др., 1989; Shigeta et al., 2015), повышающий термостабильность и термопрочность мембран клетки. Антистрессовый эффект БС связывают с глубокими изменениями физиолого-биохимических процессов, в том числе и на уровне белоксинтезирующей системы (Watt, Cresswell, 1987).

В последнее время возможность растений переносить неблагоприятное воздействие разнообразных стрессорных факторов связывают с их способностью в неблагоприятных условиях переключаться между активацией и подавлением роста (Feng et al., 2016; Bechtold, Field, 2018). При этом решающую роль в ответах как на абиотический, так и биотический стрессы могут играть пути передачи сигнала, опосредованные фитогормонами (Verma et al., 2016). Считается, что ключевым путем, контролирующим реакцию растительного организма на неблагоприятное воздействие стрессорного фактора, является сигнальный путь АБК (Yoshida et al., 2014; Zhu et al., 2017). Однако не менее убедительные доказатель- 
ства указывают на то, что БС также играют заметную роль в контроле баланса между нормальным ростом и устойчивостью к воздействию окружающей среды, действуя либо через перекрестное затухание сигналов с АБК-сигнальным путем, либо независимо (Planas-Riverola et al., 2019). Известно, что БС способствуют росту за счет активации транскрипционных факторов BZR1 и BES1 (Bechtold, Field, 2018). Недавно проведенное исследование показало, что стресс, вызванный засухой, подавляет сигнальный путь БС и, тем самым, рост клеток растения, способствуя деградации BES1 посредством убиквитинирования и селективной аутофагии (Nolan et al., 2017).

Интеграция различных гормональных сигналов опосредует целый ряд реакций развития растительного организма и реакций на окружающую среду (Vandenbussche, Van Der Straeten, 2004). За последние два десятилетия многочисленных генетических и биохимических исследований, использующих A. thaliana в качестве модельного организма, были определены и охарактеризованы основные компоненты сигнального пути БС (Li, Chory, 1997; Li, Nam, 2002; Li et al., 2002; Nam, Li, 2002; Mora-Garcia et al., 2004; Vert et al., 2005; Wang, Chory, 2006; Tang et al., 2008; Yan et al., 2009; Li, 2010; Clouse, 2011; Hothorn et al., 2011; She et al., 2011; Wang et al., 2011; Wang et al., 2012; Zhu et al., 2013; Zhu et al., 2019). Восприятие БС происходит рецепторами, локализованными в мембранах клеток, далее нисходящие цитозольные регуляторы передают БС-опосредованные сигналы в ядро, где они активируют транскрипцию БС-отзывчивых генов, которые управляют клеточным ростом (Zhao, Li, 2012; Belkhadir, Jaillais, 2015). Coответственно, мутации в генах, кодирующих основные компоненты синтеза БС, приводят к выраженной карликовости, нарушению роста и развития органов, ограничению продуктивности и урожайности растений (Li, Chory, 1997; Singh, Savaldi-Goldstein, 2015; Planas-Riverola et al., 2019). Несмотря на изученность компонентов сигнального пути БС, многие вопросы остаются неясными, в том числе клеточная специфичность БС, как сигнальный путь БС взаимодействует с другими гормональными путями при нормальных и экологически сложных сценариях и в каких тканях происходит синтез БС (Cano-Delgado, Blazquez, 2013; Vukasinovic, Russinova, 2018).

В настоящее время активно ведутся работы по расшифровке механизмов, с помощью которых БС-опосредованная сигнализация регулирует адаптацию к биотическим (De Bruyne et al., 2014) и абиотическим (LozanoDuran, Zipfel, 2015; Nolan et al., 2017) стрессам. На данный момент мировым научным сообществом предложено несколько механизмов, объясняющих, как сигнальный путь БС опосредует адаптацию к стрессу. К ним относятся: 1) точная настройка стресс-чувствительных транскрипционных механизмов (Ye et al., 2017); 2) активация антиоксидантных механизмов (Xia et al., 2009; Kim et al., 2012; Lima, Lobato, 2017; Tunc-Ozdemir, Jones, 2017; Zou et al., 2018); 3) стимулирование выработки осмопротекторов (Fabregas et al., 2018). Следовательно, БС играют ключевую роль в поддержании нормального роста растений как в нормальных условиях, так и в ответ на воздействие негативных факторов окружающей среды, и в настоящее время имеется достаточно данных, подтверждающих идею о том, что модификация сигнального пути БС может быть стратегическим направлением для разработки более адаптированных сельскохозяйственных культур.

Вышеперечисленные особенности воздействия эпибрассинолида на растения позволяют рассматривать биостимулятор 
Эпин-Экстра (действующее вещество 24-эпибрассинолид) как эффективный, экологически чистый регулятор роста и развития растений как в нормальных условиях, так и под воздействием стрессорных факторов.

\section{Протекторное действие Эпин-Экстра в условиях свинцового загрязнения среды}

Согласно данным Всемирной организации здравоохранения, среди поллютантов, оказывающих негативное влияние на человека, ТМ занимают второе место, уступая лишь пестицидам и значительно опережая такие хорошо известные загрязнители окружающей среды, как двуокись углерода и серы. Около 11 \% почв территории России имеют высокий уровень загрязнения ТМ (Титов и др., 2014). Одним из ТМ, чье количество в окружающей среде стабильно увеличивается, является $\mathrm{Pb}$. По разведанным запасам $\mathrm{Pb}$ страны Восточной Европы, Кавказа и Центральной Азии (ВЕКЦА) занимают первое место в мире. На их долю приходится 22,4 \% мировых подтвержденных запасов металла. Наиболее значительные запасы $\mathrm{Pb}$ заключены в месторождениях Казахстана (40,3 \% от запасов стран ВЕКЦА), России (36,1 \%) и Узбекистана $(11,4$ \%). На остальные страны - Азербайджан, Армению, Грузию, Киргизию, Таджикистан и Украину - приходится всего 12,2 \% запасов $\mathrm{Pb}$, разведанных в странах ВЕКЦА. 92 \% запасов $\mathrm{Pb}$ этих стран приурочены к месторождениям полиметаллических и свинцово-цинковых руд. Анализ мирового потребления $\mathrm{Pb}$ показывает увеличение процента вторичного $\mathrm{Pb}$ до 85-90 \% (Сперанская, 2008).

Основными источниками поступления и накопления $\mathrm{Pb}$ в окружающей среде с последующей интоксикацией живых организмов, в том числе и организма человека, являются предприятия цветной металлургической и химической промышленности, выбросы авто- транспорта (LeGalley et al., 2013; Muzychenko et al., 2017), переработка свинцово-кислотных аккумуляторных батарей (Liu et al., 2014), применение свинцовых красок (O’Connor et al., 2018) и т.д. С 1921 г. было налажено производство этиолированного бензина, в котором октановое число повышалось посредством использования тетраэтилсвинца, что обеспечивало антидетонационный эффект. В связи с ухудшением экологической ситуации, связанной с накоплением $\mathrm{Pb}$ в биосфере, в России, США, странах Евросоюза производство и использование этилированного бензина с присадкой тетраэтилсвинца в качестве антидетонатора были полностью запрещены к 2003 г. Исключение свинцовых добавок из бензина и запрет красок на основе $\mathrm{Pb}$ привели к незначительному снижению содержания свинца в атмосфере во всем мире (Skerfving, Bergdahl, 2015). Однако за годы использования этилированного бензина с присадкой тетраэтилсвинца содержание $\mathrm{Pb}$ в биосфере значительно увеличилось и продолжает стабильно возрастать (Давыдова, Тагасов, 2002), поэтому проблема загрязнения окружающей среды $\mathrm{Pb}$ не теряет своей актуальности.

К тому же расширение индустриализации значительно увеличивает накопление ТМ в верхнем слое почвы, особенно на сельскохозяйственных полях. Максимальные нагрузки выпадений $\mathrm{Pb}$, ведущие к деградации экосистем, наблюдаются в Московской, Владимирской, Новгородской, Рязанской, Тульской, Ростовской и Ленинградской областях России (Сперанская, 2008). В культурном агроландшафте по степени распространенности $\mathrm{Pb}$ занимает второе место, уступая лишь цинку (Zn) (Алексеев, 2008). По результатам мониторинга, проведенного Государственным комитетом санитарно-эпидемиологического надзора совместно с Институтом питания Российской академии медицинских наук, 
в целом по России в $0,8-4$ \% изученных проб пищевых продуктов наблюдалось превышение содержания ТМ, в том числе по $\mathrm{Pb}$ и кадмию (Cd) (Спринчак, 2004; Бокова, 2005).

Проблема свинцового загрязнения окружающей среды актуальна и для Казахстана (Muzychenko et al., 2017). Ежегодно в Казахстане с промышленными выбросами в атмосферный воздух поступает более 1 тыс. т $\mathrm{Pb}$. «Лидерами» в этом процессе являются Карагандинская, Восточно-Казахстанская и Южно-Казахстанская области, на долю которых приходится 99,8 \% от общего объема выбросов Рb в стране (Корчевский и др., 2010). Проблема свинцового загрязнения имеет место даже в тех городах, где отсутствуют крупные промышленные предприятия, таких как Петропавловск (Северо-Казахстанская область) и Кокшетау (Акмолинская область). Так, при определении физико-химических показателей проб талого снега (pH, содержание нитратов, $\mathrm{Zn}, \mathrm{Pb}$, меди $(\mathrm{Cu})$ и $\mathrm{Cd})$, взятых в различных точках г. Кокшетау (Казахстан), было выявлено превышение ПДК Рb в 2,7 (в пробах, взятых вблизи котельной) и 1,7 раза (в пробах, взятых вблизи автомагистрали), тогда как все остальные показатели были в пределах нормы (Грабовская, 2017а). Аналогично было выявлено превышение содержания $\mathrm{Pb}$ в пробах почвы, взятых из санитарно-защитной зоны завода им. Кирова г. Петропавловска (Казахстан) - в 2 раза, а также в пробах почвы, взятых из санитарно-защитной зоны теплоэлектростанции, - в 1,5 раза (Грабовская, 2017b).

В организм человека большая часть ТМ, в том числе и $\mathrm{Pb}$, поступает преимущественно с продуктами питания (Liu et al., 2010; Liu et al., 2014; Gardener et al., 2019; Obiora et al., 2019), а также с водой (Pragst et al., 2017) и пылевыми аэрозолями (Järup, 2003; Li et al., 2009; Absalon, Ślesak, 2010; Skerfving, Bergdahl, 2015; Maret, 2017; Bai et al., 2019). B оптимальных дозах многие ТМ являются эссенциальными для растений и животных и необходимы для протекания важнейших физиологических процессов (Немерешина и др., 2013). Если же количество ТМ, поступающих в живые организмы, превышает оптимальные значения, то это оказывает токсическое действие, способствуя проявлению различных патологий (Немерешина и др., 2011; Дрогайцева, Петрова, 2014). Особо фитотоксичными элементами считаются те, которые оказывают вредное действие на тест-организмы при концентрации в питательном растворе до 1 мг/л. К таким элементам относятся, например, ионы таких металлов, как серебро (Ag), бериллий $(\mathrm{Be})$, стронций $(\mathrm{Sr})$, ртуть $(\mathrm{Hg})$ и другие, а также, вероятно, ионы $\mathrm{Pb}$ (Алексеев, 2008).

По классификации Международного комитета по проблемам окружающей среды $\mathrm{Pb}$ относится к I классу опасности (Спитковский и др., 1994). Высокие концентрации Рb в почвах в значительной степени могут подавлять рост и развитие растений (Алексеев, 2008). $\mathrm{Pb}$ не является эссенциальным элементом, хотя и обнаруживается в каждом растении (Ильин, 1991). Описан эффект торможения метаболизма растений, который возникает из-за низкого содержания $\mathrm{Pb}$ в почве (Rout, Das, 2003). По некоторым данным, в небольших количествах он способен ускорять прорастание семян, повышать содержание крахмала и стимулировать рост (Ягодин и др., 1989, 2002). Следует отметить, что $\mathrm{Pb}$ медленнее, чем другие ТМ, поступает в растения и транспортируется из корня в надземные органы (Foroughi et al., 1982; Серегин, Иванов, 1998).

Коэффициент биологического поглощения (КБП) - показатель, характеризующий способность растений поглощать металлы из почвы, - представляет собой отношение содержания металла в растении к его содер- 
жанию в почве. По данным С.Ф. Покровской (1995), для многих растений (горох, кукуруза, овес, и т.д.) КБП Рb составляет 0,001-0,005 (для сравнения: КБП Сd для этих же культур составляет 0,01-0,5). Одна из причин низкого КБП $\mathrm{Pb}$ растениями заключается в том, что ионы $\mathrm{Pb}$ в почве быстро теряют свою подвижность, так как вступают в химические реакции с образованием малорастворимых соединений: молибдатов, сульфатов, фосфатов, карбонатов, гидроксидов, хроматов, а также поглощаются минеральными органическими коллоидами (Алексеев, 2008).

Фитотоксичность $\mathrm{Pb}$ в значительной степени нивелируется наличием в растительной клетке хорошо действующей системы инактивации элемента, проникающего в корневую систему, поэтому основная часть $\mathrm{Pb}$ задерживается в корнях растений (Серегин, Иванов, 1998). В опытах Н.Ю. Гармаш (1983) было показано, что в солому пшеницы поступает менее $1 \%$, а в ботву картофеля $2 \% \mathrm{~Pb}$, содержащегося в корнях. При этом и в зерне пшеницы, и в клубнях картофеля содержание $\mathrm{Pb}$ не зависело от дозы его внесения в почву, и лишь при концентрации 200 мг/кг оно незначительно возрастало. Но при высоких концентрациях $\mathrm{Pb}$ в почвах ингибируется всасывание железа (Fe), что проявляется развитием хлороза и существенным подавлением роста растений, снижением продуктивности и устойчивости сельскохозяйственных растений, загрязнением продуктивных органов ионами $\mathrm{Pb}$ (Алексеев, 2008).

Экспериментально установлены и доказаны следующие механизмы воздействия $\mathrm{Pb}$ на клетку. Рb взаимодействует с ДНК клетки и провоцирует мутации (Reichmayr-Lais, Kurchgessner, 1984; Реутова, Шевченко, 1992; Gichner et al., 2008; Pourrut et al., 2011; Zhang et al., 2014). Он частично ингибирует системы репарации, что снижает их эффективность, поэтому возрастает выход мутаций за счет части спонтанных и индуцированных повреждений молекул ДНК, которые в норме репарировались бы (Hartwig et al., 1990). Также $\mathrm{Pb}$ оказывает общее токсическое действие на клетку за счет образования устойчивых комплексов с аминокислотами (Venugopal, Luckey, 1978; Динева и др., 1993). Нужно учитывать и эффект суммации, обусловленный тем, что в естественных условиях на организм часто влияет не один какой-либо стрессорный фактор, происходит комплексное стрессорное воздействие среды. Н.В. Гончаровой (2005) было изучено комплексное воздействие на растения ионизирующего излучения и повышенного содержания в почве $\mathrm{Pb}$. Согласно peзультатам ее исследования, небольшие дозы облучения (2 cГр) в сочетании с разными концентрациями $\mathrm{Pb}$ вызывают антагонистические эффекты, а доза 20 сГр в этих же условиях приводит к синергизму - количество мутаций в клетках исследуемых растений достоверно увеличивается. При этом способность растений противостоять неблагоприятному воздействию стрессорных факторов (засуха, ТМ, патогены, УФ-облучение, экстремальные температуры, озон, свет высокой интенсивности, оводнение и др.) во многом зависит от антиоксидантных систем растительного организма (Hallgren, Gezelius, 1982; Hertzberg, Mac Donell, 2002; Сынзыныс и др., 2005).

Способность растений накапливать ТМ, в частности $\mathrm{Pb}$, не одинакова и зависит от их видовой принадлежности (Fan et al., 2017; Cheshmazar et al., 2018; Sihlahla et al., 2019). Вместе с тем, выявление растений-аккумуляторов имеет большое практическое значение как в плане безопасного выращивания на почвах, загрязненных токсическими элементами, так и в использовании в качестве тест-объектов в опытах по изучению посту- 
пления и распределения ксенобиотиков в различных органах растений и поиска эффективных адаптогенов. М.А. Зварих и И.Г. Миллс (Zwarich, Mills, 1982) получили экспериментальные данные, касающиеся накопления ТМ овощными растениями: овощным горохом, салатом и морковью. Эти культуры выращивали на почвах, удобренных осадками сточных вод, содержащими: $\mathrm{Zn}$ - 2920; Cd - 22; $\mathrm{Cu}-790 ; \mathrm{Pb}-408$ мг/кг сухого вещества. Под овощи внесли 55, 110 и 200 т/га воздушно-сухого вещества осадка. Почва имела $\mathrm{pH}$ 6,7 и содержала 3,5 \% углерода. В результате проведенного эксперимента было установлено, что наибольшей способностью накапливать исследуемые металлы обладает салат; например, для $\mathrm{Pb}$ этот показатель равен 1,6 мг/кг сухой массы (для сравнения: морковь - 0,9, овощной горох - 0,2 мг $\mathrm{Pb}$ на 1 кг сухой массы соответственно).

В условиях увеличивающейся «свинцовой нагрузки» на биосферу обеспечить защиту растений можно двумя путями. Во-первых, прямым воздействием на неблагоприятный фактор, т.е. снизить количество $\mathrm{Pb}$, поступающего в геосистемы. Во-вторых, активацией защитных функций самого растительного организма. Поэтому одной из основных задач является поиск различного рода адаптогенов, которые могли бы уменьшить это негативное воздействие. С точки зрения возможности практического применения перспективным представляется использование естественных фитогормонов из группы брассиностероидов. Как было отмечено рядом авторов (Ikekawa, Zhao, 1991; Li, Van Staden, 1998; Sasse, 1999; Ali et al., 2007; Kagale et al., 2007; Bajguz, Hayat, 2009; Yuan et al., 2010; Hayat et al., 2012; Jiang et al., 2013; Fang et al., 2019; Fu et al., 2019), именно БС играют основную роль в повышении устойчивости растений к таким внешним стрессорам, как экстремаль- ные температуры, засуха, ТМ, затопление, засоление, повреждение гербицидами, поражение патогенами. Главное преимущество использования БС заключается в том, что они не вредят окружающей среде, поскольку действуют в естественных дозах и естественным путем, а также не индуцируют коэволюцию вредителей (Khripach et al., 2000). В то же время применение большинства стимуляторов роста может интенсифицировать поглощение растениями из почвы минеральных соединений. По имеющимся данным, система поглощения и транспорта металлов у растений недостаточно специфична (Clemens et al., 2002). По этой причине существует опасность накопления в тканях и органах растений в избыточном количестве как неэссенциальных, так и эссенциальных элементов. Применение большинства регуляторов роста в современном растениеводстве повышает потенциальный риск превышения допустимого содержания ТМ в растениях. Однако синтетический препарат Эпин-Экстра позиционируется как универсальный стимулятор роста растений и адаптоген, применение которого нивелирует воздействие на растения таких стрессорных факторов, как воздействие экстремальных температур, засухи, повышенного содержания в почве ТМ, радионуклидов и пр., что достигается посредством стимуляции собственного иммунитета растений; он обеспечивает повышение устойчивости к заболеваниям практически у всех сельскохозяйственных культур (Шаповал и др., 2014). Следует акцентировать внимание на том, что Эпин-Экстра снижает аккумуляцию химических элементов и их соединений, находящихся в избытке, что важно для безопасности и качества растениеводческой продукции. Анализируя имеющиеся данные исследований (Bajguz, 2000; Kaur, Bhardwaj, 2003; Janeczko et al., 2005; Прусакова, Чижова, 2005; Sharma, 
Bhardwaj, 2007), можно заключить, что основной причиной уменьшения проявления токсического действия ТМ при обработке БС служит уменьшение их кумуляции в органах растения.

В настоящее время опубликовано ограниченное количество результатов исследований (Володькин, 2003; Janeczko et al., 2005; Титов и др., 2011; Hayat et al., 2012; Грузнова, 2017), непосредственно касающихся применения БС и синтетических препаратов на их основе с целью защиты сельскохозяйственных видов растений в условиях загрязнения среды TM, в частности $\mathrm{Pb}$. Например, было показано, что обработка клубней картофеля 0,4\%-ным рабочим раствором препарата Эпин-Экстра и вегетативной массы в фазе бутонизации $0,02 \%$-ным рабочим раствором снижает содержание в них $\mathrm{Pb}$, астата (At), $\mathrm{Zn}$ и $\mathrm{Cu}$ (Володькин, 2003). Обработка препаратом Эпин-Экстра (предпосевное замачивание и опрыскивание вегетирующих растений) дало положительный результат при выращивании свеклы столовой сорта «Бордо» и перца сладкого сорта «Родник» на почвах, загрязненных $\mathrm{Pb}$ и $\mathrm{Cd}$. Применение данного биостимулятора способствовало повышению урожайности и снижению концентрации ТМ в готовой продукции как свеклы, так и перца. При этом увеличение урожайности перца было максимальным и составило 20,6 \% по сравнению с контролем (Титов и др., 2011). К.А. Грузновой (2017) было показано дифференцированное влияние регуляторов роста на про- и антиоксидантную активность растений пшеницы в присутствии различных концентраций ТМ в среде, в том числе и $\mathrm{Pb}$ : регуляторы растений Цитодеф и Тидиазурон могут оказывать как синергическое, так и антагонистическое с ионами ТМ действие, тогда как Эпин-Экстра и Рибав-Экстра оказывают только антагонистическое действие, поэтому их применение в условиях загрязнения среды ТМ, в том числе и $\mathrm{Pb}$, является наиболее предпочтительным ввиду большей эффективности протектирующего действия.

В исследованиях Н.И. Грабовской (2018) при изучении протектирующего действия Эпин-Экстра на семена и растения кресссалата, которые помещали в среды с повышенным содержанием $\mathrm{Pb}$, было выявлено негативное воздействие ионов $\mathrm{Pb}$ на всхожесть семян. Концентрации общего $\mathrm{Pb}$ в среде в 50, 100 ПДК для почвы $(1600,3200$ мг/кг) и выше летальны - 100 \% семян погибало и протектирующее действие Эпин-Экстра не определялось. Ростовые показатели 10 -дневных растений, выращенных в среде с повышенным содержанием $\mathrm{Pb}$, были заметно снижены по сравнению с проростками, выращенными в бессвинцовой среде. Наибольшее токсическое воздействие $\mathrm{Pb}$ оказывал на корневую систему, подавляя ее рост и развитие. Снижение формирования корневой системы наблюдалось уже при концентрации $\mathrm{Pb}$ свыше 10 ПДК для почвы (320 мг/кг). По сравнению с контролем у тест-объектов, выращенных в среде с повышенным содержанием $\mathrm{Pb}$, формирование корневой системы блокировалось на 85-90 \%, что весьма существенно (рис. 2).

В условиях загрязнения $\mathrm{Pb}$ применение Эпин-Экстра улучшало ростовые показатели корневой системы на 11-28 \%. Влияние $\mathrm{Pb}$ на побеги было не столь выражено, как на корень. В среднем, снижение ростовых показателей побега составило 50-75 \% по сравнению с контролем. Также было замечено, что при концентрациях $\mathrm{Pb}$, близких к критическим, происходит разрушение хлорофилла и нарушение обмена веществ, что вызывает пожелтение и искривление побегов. Применение Эпин-Экстра улучшало ростовые показатели побегов на 0,7-17 \%. Таким образом, протектирующее действие препарата Эпин-Экстра 


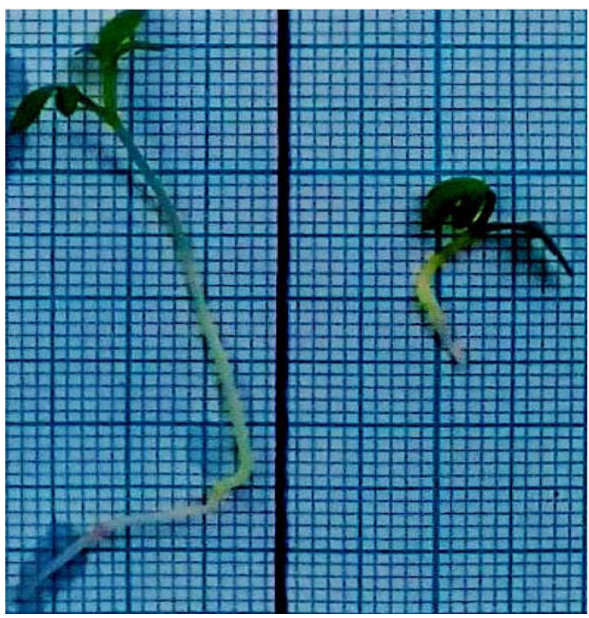

Рис. 2. Ингибирующее действие свинца на развитие корневой системы и побега у кресс-салата (Lepidium sativum) сорта Данский (фото Н.И. Грабовской). Показаны растения кресс-салата на пятый день вегетации. Слева - контрольное растение кресс-салата, выращенное в бессвинцовой среде; справа опытное растение кресс-салата, выращенное в среде с концентрацией $\mathrm{Pb} 1200$ мг/л

Fig. 2. Inhibitory effect of lead on the development of the root system and shoot in cress plants (Lepidium sativum) of the Dansky variety (photo of Grabovskaya N.I.). Cress plants on the fifth day of vegetation are shown. On the left - the cress plant grown in a lead-free medium (control); on the right - the cress plant grown in a medium with $\mathrm{Pb}$ concentration of $1200 \mathrm{mg} / \mathrm{L}$

было более выраженным на корневой системе, нежели на побеге. При концентрациях $\mathrm{Pb}$ в среде свыше 30 ПДК для почвы (960 мг/кг) рост растений значительно ингибируется. Следовательно, применение препарата ЭпинЭкстра наиболее целесообразно при концентрациях общего $\mathrm{Pb}$ около 10-30 ПДК для почвы (320-960 мг/кг).

\section{Заключение}

В связи с ухудшением экологической ситуации и деградацией экосистем разного уровня тенденция воздействия на растения неблагоприятных факторов будет нарастать, поэтому применение естественных, безопасных для окружающей среды и человека биостимуляторов является весьма перспективным направлением и требует дальнейших исследований с целью повышения эффективности и безопасности их использования. Очевидно, что данный вопрос требует дальнейшего изучения еще и ввиду того, что различные ТМ обладают разнообразными механизмами патологического действия на растительную клетку, следовательно, эффективность применения синтетических препаратов на основе БС также может значительно варьировать.

Вероятно, что подобного рода исследования целесообразно проводить методом биотестирования на проростках с использованием растений-индикаторов, так как это позволяет создать стандартизированные условия, более точно регулировать концентрацию как ТМ, так и биостимулятора, что даст более достоверные результаты по сравнению с опытами в открытом грунте.

При подборе растительных регуляторов для нивелирования того или иного стрессорного фактора необходимо учесть целый ряд детерминант. Во-первых, концентрационные эффекты регуляторов роста, направленные против стрессорных воздействий, очень зависят от вида стрессора, его дозы, особен- 
ностей растений и условий их выращивания, поэтому невозможно подобрать одну-две какие-то концентрации регуляторов роста, позволяющие эффективно бороться с абиотическим/антропогенным стрессом. Во-вторых, поскольку синтетические (а также многие природные) экзогенные регуляторы роста являются ксенобиотиками для растений, они могут оказывать как положительные, так и негативные эффекты (в норме и при стрессах). В-третьих, все фитогормоны в растении создают общую регуляторную сеть (Лукаткин, Лукаткин, 2017), и возмущение, создаваемое введением одного какого-либо дополнительного экзогенного регулятора роста, провоцирует серьезные изменения в работе целостной гормональной системы растения. К тому же при применении стимуляторов для улучшения состояния растений при стрессе, вызванном воздействием TM, в том числе и $\mathrm{Pb}$, нужно учитывать, что некоторые стимуляторы на основе фитогормонов и гормоноподобных соединений интенсифицируют накопление рас- тениями эссенциальных и неэссенциальных элементов, находящихся в среде (особенно избыточных), что в условиях избыточности ТМ в среде может ухудшить качество растениеводческой продукции или сделать ее непригодной для употребления. Тогда как при применении биостимуляторов для защиты растений от большинства неблагоприятных факторов, имеющих физическую природу (экстремальные низкие и высокие температуры, засуха и прочее), этой особенностью можно пренебречь.

Следовательно, в условиях свинцового загрязнения среды синтетические препараты на основе БС (в том числе и Эпин-Экстра), повидимому, являются приоритетными, так как не только повышают урожайность сельскохозяйственных культур в условиях химического загрязнения среды, улучшая ростовые показатели, но и положительно влияют на их качество, так как протектирующее действие достигается посредством снижения кумуляции ТМ в продуктивных органах растений.

\section{Список литературы / References}

Алексеев Ю.В. (2008) Тяжелье металль в агроландшафте. СПб., ПИЯФ РАН, 216 с. [Alekseev Yu.V. (2008) Heavy metals in agrolandscape. St. Petersburg, B.P. Konstantinov Petersburg Institute for Nuclear Physics of the Russian Academy of Sciences, 216 p. (in Russian)]

Бабенко О.Н. (2004) Влияние водного стресса и регуляторов роста на проростки пшеницы. Тезисы докладов Республиканской научно-практической конференции молодых ученых и студентов, посвященной 50-летию освоения иелины, с. 107-108 [Babenko O.N. (2004) Effect of water stress and growth regulators on wheat seedlings. Abstracts of the reports of the Republican Scientific-Practical Conference of Young Scientists and Students Dedicated to the $50^{\text {th }}$ Anniversary of the Development of Virgin Lands, p. 107-108 (in Russian)]

Бабенко О.Н., Сафронова Н.М. (2007) Влияние водного стресса и регуляторов роста на морфофизиологические показатели проростков яровой пшеницы. Стратегические вопросы мировой науки-2007, 2 (10): 24-26 [Babenko O.N., Safronova N.M. (2007) Effect of water stress and growth regulators on the morphological and physiological parameters of spring wheat seedlings. Strategic Issues of World Science-2007, 2 (10): 24-26 (in Russian)]

Бокова Т.И. (2005) Закономерности детоксикаџии антропогенных загрязнителей (тяжелых металлов) в системе почва - растение - животное - продукт питания человека. Красноярск, Красноярский государственный аграрный университет, 345 с. [Bokova T.I. (2005)

$$
-145-
$$


Regularities of detoxification of anthropogenic pollutants (heavy metals) in the soil - plant-animalhuman food system. Krasnoyarsk, Krasnoyarsk State Agrarian University, 345 p. (in Russian)]

Володькин А.А. (2003) Изменение содержания тяжелых металлов и радионуклидов в клубнях картофеля в зависимости от применения регуляторов роста. Бюллетень Всероссийского НИИ удобрений и агропочвоведения, 118: 219-221 [Volodkin A.A. (2003) Changes in the contents of heavy metals and radionuclides in potato tubers, depending on the use of growth regulators. Bulletin of the All-Russian Research Institute of Fertilizers and Soil Science [Byulleten' Vserossiyskogo NII udobreniy i agropochvovedeniya], 118: 219-221 (in Russian)]

Гайтер П. (2001) Влияние эпина на рост и развитие томатов. Тезисы докладов конференции молодых ученых СО РАН, посвященной М.А. Лаврентьеву, с. 38-42 [Gaiter P. (2001) The effect of epin on growth and development of tomatoes. Abstracts of the reports of the Conference of Young Scientists of the Siberian Branch of the Russian Academy of Sciences, Dedicated to M.A. Lavrentiev, p. 38-42 (in Russian)]

Гармаш Н.Ю. (1983) Воздействие повышенного содержания тяжелых металлов в субстрате на пшеницу и картофель. Известия Сибирского отделения Академии наук СССР. Серия биологических наук, 10-2: 84-87 [Garmash N.Yu. (1983) Effect of increased content of heavy metals in the substrate on wheat and potatoes. Proceedings of the Siberian Branch of the USSR Academy of Sciences. Biological Sciences Series [Izvestiya Sibirskogo otdeleniya Akademii nauk SSSR. Seriya biologicheskikh nauk], 10-2: 84-87 (in Russian)]

Головацкая И.Ф., Винникова Ю.М. (2007) Роль гиббереллинов и брассиностероидов в регуляции роста и развития арабидопсиса. Вестник Томского государственного педагогического университета, 6(69): 48-53 [Golovatskaya I.F., Vinnikova Y.M. (2007) The role of giberellins and brassinosteroids in reguliation of growth and development. Tomsk State Pedagogical University Bulletin [Vestnik Tomskogo gosudarstvennogo pedagogicheskogo universiteta], 6(69): 48-53 (in Russian)]

Гончарова Н.В. (2005) Растения и антропогенные стрессоры (биомониторинг). Минск, Триолета, 90 c. [Goncharova N.V. (2005) Plants and anthropogenic stressors (biomonitoring). Minsk, Trioleta, 90 p. (in Russian)]

Гончарук В.М., Быховец С.Л., Быховец А.И., Михайлопуло И.А., Ковканко Н.В., Квасюк Е.И., Кулак Т.Н., Кашкан Ж.Н. (2002) Влияние композиций 2'-5'-олигонуклеотидов и брассиностероидов на урожай клубней картофеля. Вестник института биоорганической химии НАН Беларуси, 127-129 [Goncharuk V.M., Bykhovets S.L., Bykhovets A.I., Mikhaylopulo I.A., Kovkanko N.V., Kvasyuk E.I., Kulak T.N., Kashkan Zh.N. (2002) Effect of 2'-5'-oligonucleotide and brassinosteroid compositions on potato tubers yield. Bulletin of the Institute of Bioorganic Chemistry of the National Academy of Sciences of Belarus [Vestnik instituta bioorganicheskoy khimii NAN Belarusi], 127-129 (in Russian)]

Горбылева Е.Л., Боровский Г.Б. (2018) Биостимуляторы роста и устойчивости растений терпеноидной природы и другие биологически активные соединения, полученные из хвойных пород. Известия Вузов. Прикладная химия и биотехнология, 8(4): 32-41 [Gorbyleva E.L., Borovskii G.B. (2018) Growth and stability biostimulators for plants containing terpenoids and other biologically-active compounds. Proceedings of Universities. Applied Chemistry and Biotechnology [Izvestiya Vuzov. Prikladnaya khimiya i biotekhnologiya], 8(4): 32-41 (in Russian)] 
Грабовская Н.И. (2017а) Определение уровня загрязнения окружающей среды урбоценоза свинцом на основании анализа талого снега. Материаль VII Международной научнопрактической конференции «Эколого-экономическая эффективность природопользования на современном этапе развития Западно-Сибирского региона», c. 10-13 [Grabovskaya N.I. (2017a) Determining the level of environmental contamination of urban ecosystem by lead based on analysis of thawed snow. Proceedings of the VII International Scientific and Practical Conference "Environmental and Economic Efficiency of Nature Management at the Present Stage of Development of the West Siberian Region", p. 10-13 (in Russian)]

Грабовская Н.И. (2017b) Определение загрязненности почвы свинцом в пределах городской черты Петропавловска (Северо-Казахстанская область). Материалы VII Международной научно-практической конференции «Эколого-экономическая эффективность природопользования на современном этапе развития Западно-Сибирского региона», с. 13-15 [Grabovskaya N.I. (2017b) Determination of soil pollution by lead within the city limits of Petropavlovsk (North Kazakhstan Region). Proceedings of the VII International Scientific and Practical Conference "Environmental and Economic Efficiency of Nature Management at the Present Stage of Development of the West Siberian Region", p. 13-15 (in Russian)]

Грабовская Н.И. (2018) Защитное действие эпина на растения в условиях загрязнения среды свинцом на примере кресс-салата (Lepidium sativum). Приоритетные векторы развития промышленности и сельского хозяйства, 1(3): 57-61 [Grabovskaya N.I. (2018) Protective effect of epin on plants in the conditions of environmental pollution with lead by the example of cress (Lepidium sativum). Priority Vectors for the Development of Industry and Agriculture, 1(3): 57-61 (in Russian)]

Грузнова К.А. (2017) Влияние экзогенных регуляторов роста на степень токсичности тяжельх металлов в растениях пшеницы. М., РГАУ-МСХА им. К.А. Тимирязева, 24 с. [Gruznova K.A. (2017) The effect of exogenous growth regulators on the toxicity of heavy metals in wheat plants. Moscow, Russian State Agrarian University- Timiryazev Moscow Agricultural Academy, 24 p. (in Russian)]

Давыдова С.Л., Тагасов В.И. (2002) Тяжелье металлы как супертоксиканты ХХІ века. М., Изд-во РУДН, 140 с. [Davydova S.L., Tagasov V.I. (2002) Heavy Metals as Supertoxicants of the 21st Century. Moscow, RUDN University, 140 p. (in Russian)]

Динева С.Б., Абрамов В.И., Шевченко В.А. (1993) Генетические последствия действия нитрата свинца на семена хронически облучаемых популяций Arabidopsis thaliana. Генетика, 29(11): 1914-1919 [Dineva S.B., Abramov V.I., Shevchenko V.A. (1993) Genetic effects of lead nitrate on seeds of chronically irradiated populations of Arabidopsis thaliana. Genetics [Genetika], 29(11): 1914-1919 (in Russian)]

Дрогайцева А.А., Петрова Г.В. (2014) Накопление тяжелых металлов в экосистеме «почва - растения» Melampyrum arvense L. степной зоны оренбургского Предуралья. Известия Оренбургского государственного аграрного университета, 6(50): 144-146 [Drogaitseva A.A., Petrova G.V. (2014) Accumulation of heavy metals in the ecosystem "soil - plants" Melampyrum arvense L. in the steppe zone of the Orenburg Urals. Newsletter of Orenburg State Agrarian University [Izvestiya Orenburgskogo gosudarstvennogo agrarnogo universiteta], 6(50): 144-146 (in Russian)]

Елагина Е.М., Вьюгина Г.В. (2001) Ростовые и фотосинтетические показатели проростков огурцов в связи с пикировкой и обработкой эпибрассинолидом. Актуальные вопросы эко-

$$
-147-
$$


логической физиологии растений в ХХI веке, с. 220-221 [Yelagina E.M., Vyugina G.V. (2001) Growth and photosynthetic parameters of cucumber seedlings in connection with top removal and epibrassinolide treatment. Current Issues of Plant Ecological Physiology in the XXI Century, p. 220221 (in Russian)]

Зубарев А.В. (2001) Влияние эпибрассинолида на процесс каллусогенеза и содержание нуклеиновых кислот в листовых дисках табака (Nicotiana tabacum L.). Tезисы докладов конференции молодых ученых СО РАН, посвященной М.А. Лаврентьеву, с. 43-44 [Zubarev A.V. (2001) Effect of epibrassinolide on callusogenesis and nucleic acid content in tobacco leaf disks (Nicotiana tabacum L.). Abstracts of the Reports of the Conference of Young Scientists of the Siberian Branch of the Russian Academy of Sciences Dedicated to M.A. Lavrentiev, p. 43-44 (in Russian)]

Ильин В.Б. (1991) Тяжелые металлы в системе почва - растение. Новосибирск, Наука, 151 c. [Ilyin V.B. (1991) Heavy metals in the soil-plant system. Novosibirsk, Nauka, 151 p. (in Russian)]

Корчевский А., Яковлева Н., Мартынова В., Избакиев А., Идаятов П. (2010) Оценка загрязнения окружающей среды Республики Казахстан свинцом, разработка подходов к снижению экологических рисков. VI Международная научно-практической конференция «Тяжѐлье металльь и радионуклиды в окружающей среде», с. 230-233 [Korchevsky A., Yakovleva N., Martynov V., Izbakiev A., Idayatov P. (2010) Assessment of environmental pollution of Kazakhstan by lead, the development of approaches to reduce environmental risks. VI International ScientificPractical Conference «Heavy Metals and Radionuclides in the Environment», p. 230-233 (in Russian)]

Кретович В.Л. (1986) Биохимия растений. М., Наука, 504 с. [Kretovich V.L. (1986) Biochemistry of plants. Moscow, Nauka, 504 p. (in Russian)]

Кукреш С.П., Ходянкова С.Ф. (2002) Повышение урожайности и качества льна-долгунца. Текстильный вестник, с. 24-28 [Kukresh S.P., Khodyankova S.F. (2002) Enhancing productivity and quality of long-fibred flax. Textile Bulletin, p. 24-28 (in Russian)]

Кулаева О.Н., Бурханова Э.А., Федина А.Б. (1989) Брассиностероиды в регуляции синтеза белка в листьях пшеницы. Доклады АН СССР, 305(5): 1277-1279 [Kulaeva O.N., Burkhanova E.A., Fedina A.B. (1989) Brassinosteroids in the regulation of protein synthesis in wheat leaves. Reports of the USSR Academy of Sciences [Doklady AN SSSR], 305(5): 1277-1279 (in Russian)]

Лукаткин А.С., Лукаткин А.А. (2017) Повышение устойчивости сельскохозяйственных растений к абиотическим стрессорам обработкой экзогенными регуляторами роста. Материаль международной научно-практической конференции. Агрохимикаты в XXI веке: теория и практика применения, с. 69 [Lukatkin A.S., Lukatkin A.A. (2017) Increasing the resistance of agricultural plants to abiotic stressors by treatment with exogenous growth regulators. Proceedings of the International Scientific-Practical Conference. Agrochemicals in the XXI Century: Theory and Practice of Application, p. 69 (in Russian)]

Муромцев Г.С., Чкаников Д.Н., Кулаева О.Н., Гамбург К.З. (1987) Основы химической регулящии роста и продуктивности растений. М., Агропромиздат, 383 с. [Muromtsev G.S., Chkanikov D.N., Kulaeva O.N., Hamburg K.Z. (1987) Fundamentals of chemical regulation of plant growth and productivity. Moscow, Agropromizdat, 383 p. (in Russian)]

Немерешина О.Н., Гусев Н.Ф., Филиппова А.В. (2013) Содержание водорастворимых антиоксидантов и микроэлементов в образцах чая. Успехи современного естествознания, 11: 54-64 [Nemereshina O.N., Gusev N.F., Filippova A.V. (2013) Contents water-soluble antioxidants 
and trace elements in tea samples. Advances in Current Natural Sciences [Uspekhi sovremennogo estestvoznaniya], 11: 54-64 (in Russian)]

Немерешина О.Н., Гусев Н.Ф., Чуклова Н.В., Трубников В.В. (2011) Особенности накопления эссенциальных и токсических элементов в надземной части Linaria vulgaris L. на шламовом поле криолитового производства. Вестник Оренбургского государственного университеma, 12(131): 222-224 [Nemereshina O.N., Gusev N.F., Chuklova N.V., Trubnikov V.V. (2011) Contents essential elements in the grass Linaria vulgaris L. in the field cryolite plant sludge. Vestnik of the Orenburg State University [Vestnik Orenburgskogo gosudarstvennogo universiteta], 12(131): 222-224 (in Russian)]

Озолина Н.В., Прадедова Е.В., Сапега Ю.Г., Павловская О.С., Саляев Р.К. (2007) Влияние обработок фитогормонами на биомассу и накопление сахаров в корнеплодах столовой свеклы (Beta vulgaris L.). Агрохимия, 1: 47-51 [Ozolina N.V., Pradedova E.V., Sapega Yu.G., Pavlovskaya O.S., Salyaev R.K. (2007) The effect of phytohormone treatments on biomass and sugar accumulation in table beet roots (Beta vulgaris L.). Agrochemistry [Agrokhimiya], 1: 47-51 (in Russian)]

Покровская С.Ф. (1995) Регулирование поведения свинца и кадмия в системе почва-растение. М., Наука, 51 c. [Pokrovskaya S.F. (1995) Regulation of the behavior of lead and cadmium in the soil - plant system. Moscow, Nauka, 51 p. (in Russian)]

Пономаренко С.П. (1999) Регуляторы роста растений на основе $\mathrm{N}$-оксидов производных пиридина (физико-химические свойства и биологическая активность). Киев, Техника, 270 c. [Ponomarenko S.P. (1999) Plant growth regulators based on n-oxides of pyridine derivatives (physicochemical properties and biological activity). Kiev, Technika, 270 p. (in Russian)]

Попова М.П. (2001) Полиоксистероиды (экди- и брассиностероиды) - регуляторы роста и повышения продуктивности картофеля. Тезисы докладов конференции молодых ученых СО РАН, посвященной М.А. Лаврентьеву, с. 35-36 [Popova M.P. (2001) Polyoxysteroids (ecdi- and brassinosteroids) - regulators of growth and increase in productivity of potatoes. Abstracts of the Reports of the Conference of Young Scientists of the Siberian Branch of the Russian Academy of Sciences Dedicated to M.A. Lavrentiev, p. 35-36 (in Russian)]

Прадедова Е.В. (2001) Влияние эпибрассинолида на активность $\mathrm{H}^{+}$-АТФазы и $\mathrm{H}^{+}$пирофосфатазы тонопласта корнеплода столовой свеклы (Beta vulgaris L.). Teзисы докладов конференции молодых ученых СО РАН, посвященной М.А. Лаврентьеву, с. 51-52 [Pradedova E.V. (2001) Effect of epibrassinolide on the activity of $\mathrm{H}^{+}$-ATPase and $\mathrm{H}^{+}$-pyrophosphatase of the tonoplast of beet edible root (Beta vulgaris L.). Abstracts of the Reports of the Conference of Young Scientists of the Siberian Branch of the Russian Academy of Sciences Dedicated to M.A. Lavrentiev, p. 51-52 (in Russian)]

Прусакова Л.Д., Чижова С.И. (2005) Применение брассиностероидов в экстремальных для растений условиях. Агрохимия, 7: 87-94 [Prusakova L.D., Chizhova S.I. (2005) Application of brassinosteroids in extreme conditions for plants. Agrochemistry [Agrokhimiya], 7: 87-94 (in Russian)]

Пустовойтова Т.Н. (1990) Роль фитогормонов в засухоустойчивости. Физиология растений, 2: 110 [Pustovoitova T.N. (1990) The role of phytohormones in drought resistance. Plant Physiology [Fiziologiya rastenii], 2: 110 (in Russian)]

Реутова Н.В., Шевченко В.А. (1992) Мутагенное действие неорганических соединений серебра и свинца на традесканцию. Генетика, 28(9): 89-96 [Reutova N.V., Shevchenko V.A. (1992)

$$
-149-
$$


Mutagenic effect of inorganic silver and lead compounds on Tradescantia. Genetics [Genetika], 28(9): 89-96 (in Russian)]

Сафронова Н.М., Бабенко О.Н. (2008) Действие регуляторов роста на проростки яровой пшеницы при водном стрессе. Вестник Евразийского национального университета им. Л.Н. Гумилева, 6(67): 83-90 [Safronova N.M., Babenko O.N. (2008) Effect of growth regulators on seedlings of spring wheat under water stress. Bulletin of L.N. Gumilev Eurasian National University [Vestnik Evraziiskogo natsional'nogo universiteta im. L.N. Gumilyova], 6(67): 83-90 (in Russian)]

Серегин И.В., Иванов В.Б. (1998) Передвижение ионов кадмия и свинца по тканям корня. Физиология растений, 45(6): 899-905 [Seregin I.V., Ivanov V.B. (1998) Movement of cadmium and lead ions through root tissues. Plant Physiology [Fiziologiya rastenii], 45(6): 899-905 (in Russian)]

Сперанская О. (2008) Обзор проблемы загрязнения кадмием, свинцом и ртутью окружающей среды в России и Украине. М., Центр «Эко-Согласие», 60 с. [Speranskaya O. (2008) Review of the problem of environmental pollution with cadmium, lead and mercury in Russia and Ukraine. M., Center «Eco-Soglasie», 60 p. (in Russian)]

Спитковский Д.М., Ермаков А.В., Горин А.И., Поспехова Н.И., Сорокина Т.А., Талызина Т.А. (1994) Особенности внепланового синтеза ДНК и изменений структурных параметров ядер лимфоцитов человека после действия рентгеновского излучения в малых дозах и в сочетании с УФ-облучением. Радиачионная биология. Радиоэкология, 34(1): 23-31 [Spitkovskiy D.M., Ermakov A.V., Gorin A.I., Pospekhova N.I., Sorokinna T.A., Talyzina T.A. (1994) The characteristics of unscheduled DNA synthesis and of the changes in the structural parameters of human lymphocyte nuclei after the action of X-ray radiation in low doses and in combination with UV irradiation. Radiation Biology. Radioecology [Radiacionnaya biologiya. Radioekologiya], 34(1): 23-31 (in Russian)]

Спринчак Д.В. (2004) Детоксикаџия тяжелых металлов (свинца, кадмия) в системе «почва - растение - животное». Красноярск, Красноярский государственный аграрный университет, 119 c. [Sprinchak D.V. (2004) Detoxification of heavy metals (lead, cadmium) in the "soil plant-animal» system. Krasnoyarsk, Krasnoyarsk State Agrarian University, 119 p. (in Russian)]

Стрельцова В.А., Ольховик В.К. (1990) Влияние природных и синтетических брассиностероидов на урожай ячменя. Доклады ВАСХНИЛ, 6: 7 [Streltsova V.A., Olkhovik V.K. (1990) Effect of natural and synthetic brassinosteroids on barley harvest. Reports of Lenin All-Union Academy of Agricultural Sciences [Doklady VASKHNIL], 6: 7 (in Russian)]

Сынзыныс Б.И., Тянтова Е.Н., Момот О.А., Козьмин Г.В. (2005) Техногенный риск и методология его оценки. Обнинск, 76 с. [Synzynys B.I., Tiantova E.N., Momot O.A., Kozmin G.V. (2005) Technogenic risk and methodology for its assessment. Obninsk, 76 p. (in Russian)]

Титов А.Ф., Казнина Н.М., Таланова В.В. (2014) Тяжелье металлы и растения. Петрозаводск, Карельский научный центр РАН, 194 с. [Titov A.F., Kaznina N.M., Talanova V.V. (2014) Heavy metals and plants. Petrozavodsk, Karelian Scientific Center of the Russian Academy of Sciences, 194 p. (in Russian)]

Титов В.Н., Смыслов Д.Г., Дмитриева Г.А., Болотова О.И. (2011) Регуляторы роста растений как биологический фактор снижения уровня тяжелых металлов в растении. Вестник Орловского государственного аграрного университета, 4(31): 4-6 [Titov V.N., Smyslov D.G., Dmitrieva G.A., Bolotova O.I. (2011) Plant growth regulators as a biological factor in reducing the 
level of heavy metals in a plant. Bulletin of the Orel State Agrarian University [Vestnik Orlovskogo gosudarstvennogo agrarnogo universiteta], 4(31): 4-6 (in Russian)]

Тищенко С.Ю., Карначук Р.А., Хрипач В.А. (2001а) Участие эпибрассинолида в фоторегуляции роста и гормонального баланса арабидопсиса на синем свету. Вестник Башкирского университета, 2: 166-167 [Tishchenko S.Yu., Karnachuk R.A., Khripach V.A. (2001a) Involvement of epibrassinolide in photoregulation of growth and hormonal balance of arabidopsis in blue light. Bulletin of Bashkir University [Vestnik Bashkirskogo universiteta], 2: 166-167 (in Russian)]

Тищенко С.Ю., Карначук Р.А., Хрипач В.А. (2001b) Брассиностероиды и свет как факторы регуляции роста растений. Актуальные вопросы экологической физиологии растений в XXI веке, c. 349-350 [Tishchenko S.Yu., Karnachuk R.A., Khripach V.A. (2001b) Brassinosteroids and light as factors regulating plant growth. Current Issues of Plant Ecological Physiology in the XXI Century, p. 349-350 (in Russian)]

Шаповал О.А., Можарова И.П., Коршунов А.А. (2014) Регуляторы роста растений в агротехнологиях. Защчта и карантин растений, 6: 16-20 [Shapoval O.A., Mozharova I.P., Korshunov A.A. (2014) Plant growth regulators in agrotechnologies. Plant Protection and Quarantine [Zashchita i karantin rastenii], 6: 16-20 (in Russian)]

Ягодин Б.А., Смирнов П.М., Петербургский А.В. (1989) Агрохимия. Ягодин Б.А. (ред.) М., Агропромиздат, 639 с. [Yagodin B.A., Smirnov P.M., Peterburgskii A.V. (1989) Agrochemistry. Yagodin B.A. (ed.) Moscow, Agropromizdat, 639 p. (in Russian)]

Ягодин Б.А., Жуков Ю.П., Кобзаренко В.И. (2002) Агрохимия. М., Колос, 584 с. [Yagodin В.А., Zhukov Y.P., Kobzarenko V.I. (2002) Agrochemistry. Moscow, Kolos, 584 p. (in Russian)]

Яхин О.И., Лубянов А.А., Серегин И.В., Яхин И.А. (2014) Влияние регуляторов роста на накопление тяжелых металлов и проявление их токсического действия у высших растений. Агрохимия, 12: 61-78 [Yakhin O.I., Lubyanov A.A., Seregin I.V., Yakhin I.A. (2014) Effect of plant growth regulators on the accumulation of heavy metals and their toxic action in higher plants. Agrochemistry [Agrohimiya], 12: 61-78 (in Russian)]

Abe H. (1989) Advances in brassinosteroid research and prospects for its agricultural application. Japan Pesticide Information, 55: 10-14

Abe H., Morishita T., Uchiyama M., Takatsuto S., Ikekawa N. (1984) A new brassinolide-related steroid in the leaves of Thea sinensis. Agricultural and Biological Chemistry, 48(8): 2171-2172

Absalon D., Ślesak B. (2010) The effects of changes in cadmium and lead air pollution on cancer incidence in children. Science of the Total Environment, 408(20): 4420-4428

Achard P., Vriezen W.H., Van Der Straeten D., Harberd N.P. (2003) Ethylene regulates Arabidopsis development via the modulation of DELLA protein growth repressor function. Plant Cell, 15(12): 28162825

Alazem M., Lin N.-S. (2015) Roles of plant hormones in the regulation of host-virus interactions. Molecular Plant Pathology, 16(5): 529-540

Albrecht C., Boutrot F., Segonzac C., Schwessinger B., Gimenez-Ibanez S., Chinchilla D., Rathjen J.P., de Vries S.C., Zipfel C. (2012) Brassinosteroids inhibit pathogen-associated molecular pattern-triggered immune signaling independent of the receptor kinase BAK1. Proceedings of the National Academy of Sciences of the United States of America, 109(1): 303-308 
Ali B. (2017) Practical applications of brassinosteroids in horticulture - some field perspectives. Scientia Horticulturae, 225: 15-21

Ali B., Hasan S.A., Hayat S., Hayat Q., Yadav S., Fariduddin Q., Ahmad A. (2008) A role of brassinosteroids in the amelioration of aluminium stress through antioxidant system in mung bean (Vigna radiata L. Wilczek). Environmental and Experimental Botany, 62(2): 153-159

Ali B., Hayat S., Ahmad A. (2007) 28-homobrassinolide ameliorates the saline stress in chickpea (Cicer arietinum L.). Environmental and Experimental Botany, 59(2): 217-223

Allagulova C.R., Maslennikova D.R., Avalbaev A.M., Fedorova K.A., Yuldashev R.A., Shakirova F.M. (2015) Influence of 24-epibrassinolide on growth of wheat plants and the content of dehydrins under cadmium stress. Russian Journal of Plant Physiology, 62(4): 465-471

An F., Zhang X., Zhu Z., Ji Y., He W., Jiang Z., Li M., Guo H. (2012) Coordinated regulation of apical hook development by gibberellins and ethylene in etiolated Arabidopsis seedlings. Cell Research, 22(5): 915-927

Bai M.Y., Shang J.X., Oh E., Fan M., Bai Y., Zentella R., Sun T.P., Wang Z.Y. (2012) Brassinosteroid, gibberellin and phytochrome impinge on a common transcription module in Arabidopsis. Nature Cell Biology, 14(8): 810-U78

Bai Y., Laenen A., Haufroid V., Nawrot T.S., Nemery B. (2019) Urinary lead in relation to combustion-derived air pollution in urban environments. A longitudinal study of an international panel. Environment International, 125: 75-81

Bajguz A. (2000) Blockade of heavy metals accumulation in Chlorella vulgaris cells by 24-epibrassinolide. Plant Physiology and Biochemistry, 38(10): 797-801

Bajguz A. (2009) Brassinosteroid enhanced the level of abscisic acid in Chlorella vulgaris subjected to short-term heat stress. Journal of Plant Physiology, 166(8): 882-886

Bajguz A., Hayat S. (2009) Effects of brassinosteroids on the plant responses to environmental stresses. Plant Physiology and Biochemistry, 47(1): 1-8

Bao F., Shen J.J., Brady S.R., Muday G.K., Asami T., Yang Z.B. (2004) Brassinosteroids interact with auxin to promote lateral root development in Arabidopsis. Plant Physiology, 134(4): 1624-1631

Bechtold U., Field B. (2018) Molecular mechanisms controlling plant growth during abiotic stress. Journal of Experimental Botany, 69(11): 2753-2758

Belkhadir Y., Jaillais Y. (2015) The molecular circuitry of brassinosteroid signaling. New Phytologist, 206(2): 522-540

Bhattacharya A. (2019) Chapter 6 - Effect of high-temperature stress on the metabolism of plant growth regulators. Effect of high temperature on crop productivity and metabolism of macro molecules. Bhattacharya A. (ed.) Cambridge, Massachusetts, Academic Press, p. 485-591

Bishop G.J., Yokota T. (2001) Plants steroid hormones, brassinosteroids: current highlights of molecular aspects on their synthesis/metabolism, transport, perception and response. Plant and Cell Physiology, 42(2): 114-120

Boerjan W., Cervera M.T., Delarue M., Beeckman T., Dewitte W., Bellini C., Caboche M., Van Onckelen H., Van Montagu M., Inzé D. (1995) Superroot, a recessive mutation in Arabidopsis, confers auxin overproduction. Plant Cell, 7(9): 1405-1419

Budaj S.I. (2000) Germinating capacity and morphophysiological peculiarities of developing carrot plants under treatment by growth regulators. Proceedings of the National Academy of Sciences 
of Belarus. Biological Series [Izvestiya Nacional'noj akademii nauk Belarusi. Seriya biologicheskih nauk], 3: 38-41

Cai J.H., Luo F., Zhao Y.B., Zhou Q., Wei B.D., Zhou X., Ji S.J. (2019) 24-epibrassinolide treatment regulates broccoli yellowing during shelf life. Postharvest Biology and Technology, 154: 87-95

Campbell P., Braam J. (1998) Co- and/or post-translational modifications are critical for TCH4 XET activity. Plant Journal, 15(4): 553-561

Cano-Delgado A., Yin Y.H., Yu C., Vafeados D., Mora-Garcia S., Cheng J.C., Nam K.H., Li J.M., Chory J. (2004) BRL1 and BRL3 are novel brassinosteroid receptors that function in vascular differentiation in Arabidopsis. Development, 131(21): 5341-5351

Cano-Delgado A.I., Blazquez M.A. (2013) Spatial control of plant steroid signaling. Trends in Plant Science, 18(5): 235-236

Cheshmazar E., Arfaeinia H., Karimyan K., Sharafi H., Hashemi S.E. (2018) Dataset for effect comparison of irrigation by wastewater and ground water on amount of heavy metals in soil and vegetables: Accumulation, transfer factor and health risk assessment. Data in Brief, 18: 1702-1710

Choe S., Dilkes B.P., Gregory B.D., Ross A.S., Yuan H., Noguchi T., Fujioka S., Takatsuto S., Tanaka A., Yoshida S., Tax F.E., Feldmann K.A. (1999) The Arabidopsis dwarf1 mutant is defective in the conversion of 24-methylenecholesterol to campesterol in brassinosteroid biosynthesis. Plant Physiology, 119(3): 897-907

Clemens S., Palmgren M.G., Krämer U. (2002) A long way ahead: understanding and engineering plant metal accumulation. Trends in Plant Science, 7(7): 309-315

Clouse S.D. (2011) Brassinosteroid signal transduction: from receptor kinase activation to transcriptional networks regulating plant development. Plant Cell, 23(4): 1219-1230

Clouse S.D., Langford M., McMorris T.C. (1996) A brassinosteroid-insensitive mutant in Arabidopsis thaliana exhibits multiple defects in growth and development. Plant Physiology, 111(3): 671-678

Clouse S.D., Sasse J.M. (1998) Brassinosteroids: essential regulators of plant growth and development. Annual Review of Plant Physiology and Plant Molecular Biology, 49: 427-451

Dahse I., Sack H., Bernstein M., Petzold U., Müller E., Vorbrodt H.M., Adam G. (1990) Effects of (22S, 23S)-homobrassinolide and related compounds on membrane potential and transport of Egeria leaf cells. Plant Physiology, 93(3): 1268-1271

Davies P.J. (2004) Plant hormones biosynthesis, signal transduction action. Dordrecht, Boston, London, Kluwer Academic Publisher, 750 p.

De Bruyne L., Höfte M., De Vleesschauwer D. (2014) Connecting growth and defense: the emerging roles of brassinosteroids and gibberellins in plant innate immunity. Molecular Plant, 7(6): 943-959

De Grauwe L., Vandenbussche F., Tietz O., Palme K., Van Der Straeten D. (2005) Auxin, ethylene and brassinosteroids: Tripartite control of growth in the Arabidopsis hypocotyl. Plant and Cell Physiology, 46(6): 827-836

Deng X.-G., Zhu T., Zou L.-J., Han X.Y., Zhou X., Xi D.H., Zhang D.W., Lin H.H. (2016) Orchestration of hydrogen peroxide and nitric oxide in brassinosteroid-mediated systemic virus resistance in Nicotiana benthamiana. Plant Journal, 85(4): 478-493

Fabregas N., Lozano-Elena F., Blasco-Escamez D., Tohge T., Martinez-Andujar C., Albacete A., Osorio S., Bustamante M., Riechmann J.L., Nomura T., Yokota T., Conesa A., Pérez 
Alfocea F., Fernie A.R., Cano-Delgado A.I. (2018) Overexpression of the vascular brassinosteroid receptor BRL3 confers drought resistance without penalizing plant growth. Nature Communications, 9: 4680

Fan Y., Li H., Xue Z., Zhang Q., Cheng F. (2017) Accumulation characteristics and potential risk of heavy metals in soil-vegetable system under greenhouse cultivation condition in Northern China. Ecological Engineering, 102: 367-373

Fang P.P., Yan M.Y., Chi C., Wang M.Q., Zhou Y.H., Zhou J., Shi K., Xia X.J., Foyer C.H., Yu J.Q. (2019) Brassinosteroids act as a positive regulator of photoprotection in response to chilling stress. Plant Physiology, 180(4): 2061-2076

Fariduddin Q., Yusuf M., Ahmad I., Ahmad A. (2014) Brassinosteroids and their role in response of plants to abiotic stresses. Biologia Plantarum, 58(1): 9-17

Feng W., Lindner H., Robbins N.E., Dinneny J.R. (2016) Growing out of stress: the role of celland organ-scale growth control in plant water-stress responses. Plant Cell, 28(8): 1769-1782

Filek M., Rudolphi-Skórska E., Sieprawska A., Kvasnica M., Janeczko A. (2017) Regulation of the membrane structure by brassinosteroids and progesterone in winter wheat seedlings exposed to low temperature. Steroids, 128: 37-45

Forgac M. (1998) Structure, function and regulation of the vacuolar $(\mathrm{H}+)$-ATPases. FEBS Letters, 440(3): 258-263

Foroughi M., Venter F., Teicher K. (1982) Experimentalle ermittlung der schwermetallanreicherung und verteilung in buschbohnen (Phaseolus vulgaris L.). Landwirtschaftliche Forschung, 32(38): 239248 (in German)

Fu J., Sun P., Luo Y., Zhou H., Gao J., Zhao D., Pubu Z., Liu J., Hu T. (2019) Brassinosteroids enhance cold tolerance in Elymus nutans via mediating redox homeostasis and proline biosynthesis. Environmental and Experimental Botany, 167: 103831

Fujioka S., Choi Y.H., Takatsuto S., Yokota T., Li J.M., Chory J., Sakurai A. (1996) Identification of castasterone, 6-deoxocastasterone, typhasterol and 6-deoxotyphasterol from the shoots of Arabidopsis thaliana. Plant and Cell Physiology, 37(8): 1201-1203

Fujioka S., Sakurai A. (1997) Biosynthesis and metabolism of brassinosteroids. Physiologia Plantarum, 100(3): 710-715

Gardener H., Bowen J., Callan S.P. (2019) Lead and cadmium contamination in a large sample of United States infant formulas and baby foods. Science of the Total Environment, 651(1): 822-827

Gichner T., Žnidar I., Száková J. (2008) Evaluation of DNA damage and mutagenicity induced by lead in tobacco plants. Mutation Research. Genetic Toxicology and Environmental Mutagenesis, 652(2): 186-190

Glyan'ko A.K. (2018) Phytohormones and morphogenesis of root nodules and lateral roots of a legume plant. Journal of Stress Physiology \& Biochemistry, 14(3): 12-26

Gomes M.M.A., Campostrini E., Leal N.R., Viana A.P., Ferraz T.M., Siqueira L.N., Rosa R.C.C., Netto A.T., Nuñez-Vázquez M., Zullo M.A.T. (2006) Brassinosteroid analogue effects on the yield of yellow passion fruit plants (Passiflora edulis f. flavicarpa). Scientia Horticulturae, 110(3): 235-240

Gonzalez-Garcia M.P., Vilarrasa-Blasi J., Zhiponova M., Divol F., Mora-Garcia S., Russinova E., Cano-Delgado A.I. (2011) Brassinosteroids control meristem size by promoting cell cycle progression in Arabidopsis roots. Development, 138(5): 849-859 
Grove M.D., Spencer G.F., Rohwedder W.K., Mandava N., Worley J.F., Warthen J.D., Steffens G.L., Flippen-Anderson J.L., Cook J.C. (1979) Brassinolide, a plant growth-promoting steroid isolated from Brassica napus pollen. Nature, 281(5728): 216-217

Hallgren J.E., Gezelius K. (1982) Effect of $\mathrm{SO}_{2}$ on photosynthesis and ribulose bisphosphate carboxylase in pine tree seedlings. Physiologia Plantarum, 54(2): 153-161

Hartwig A., Schlepegrell R., Beyersmann D. (1990) Indirect mechanism of lead-induced genotoxicity in cultured mammalian cells. Mutation Research, 241(1): 75-82

Hassan A., Hassan Abou El Wafa M. (1947) An oestrogenic substance in pollen-grains of date palm tree Phoenix dactylifera L., Palmae. Nature, 159(4038): 409-410

Hayat S., Alyemeni M.N., Hasan S.A. (2012) Foliar spray of brassinosteroid enhances yield and quality of Solanum lycopersicum under cadmium stress. Saudi Journal of Biological Sciences, 19(3): $325-335$

He J., Wang Y.J., Ding H.D., Ge C.L. (2016) Epibrassinolide confers zinc stress tolerance by regulating antioxidant enzyme responses, osmolytes, and hormonal balance in Solanum melongena seedlings. Brazilian Journal of Botany, 39(1): 295-303

Hertzberg R.C., Mac Donell M.M. (2002) Synergy and other ineffective mixture risk definitions. Science of the Total Environment, 288(1-2): 31-42

Hothorn M., Belkhadir Y., Dreux M., Dabi T., Noel J.P., Wilson I.A., Chory J. (2011) Structural basis of steroid hormone perception by the receptor kinase BRI1. Nature, 474(7352): 467-471

Ikekawa N., Zhao Y.J. (1991) Application of 24-epibrassinolide in agriculture. ACS Symposium Series, 474: 280-291

Iliev E.A., Xu W., Polisensky D.H., Oh M.H., Torisky R.S., Clouse S.D., Braam J. (2002) Transcriptional and posttranscriptional regulation of Arabidopsis TCH4 expression by diverse stimuli. Roles of cis regions and brassinosteroids. Plant Physiology, 130(2): 770-783

Iwasaki T., Shibaoka H. (1991) Brassinosteroids act as regulators of tracheary-element differentiation in isolated Zinnia mesophyll-cells. Plant and Cell Physiology, 32(7): 1007-1014

Janeczko A., Koscielniak J., Pilipowicz M., Szarek-Lukaszewska G., Skoczowski A. (2005) Protection of winter rape photosystem 2 by 24 -epibrassinolide under cadmium stress. Photosynthetica, 43(2): 293-298

Janeczko A., Pociecha E., Dziurka M., Jurczyk B., Libik-Konieczny M., Oklestkova J., Novák O., Pilarska M., Filek M., Rudolphi-Skórska E., Sadura I., Siwek A. (2019) Changes in content of steroid regulators during cold hardening of winter wheat - Steroid physiological/biochemical activity and impact on frost tolerance. Plant Physiology and Biochemistry, 139: 215-228

Järup L. (2003) Hazards of heavy metal contamination. British Medical Bulletin, 68: 167-182

Jiang Y.P., Huang L.F., Cheng F., Zhou Y.H., Xia X.J., Mao W.H., Shi K., Yu J.Q. (2013) Brassinosteroids accelerate recovery of photosynthetic apparatus from cold stress by balancing the electron partitioning, carboxylation and redox homeostasis in cucumber. Physiologia Plantarum, 148(1): $133-145$

Jones T.K., Roddick J.G. (1977) Effects of steroidal estrogens and gibberellic acid on stem elongation in tall and dwarf cultivars of Pisum sativum. New Phytologist, 79(3): 493-499

Kabashnikova L.F., Klimovich A.S., Ling S.S., Mikhailova S.A., Chaika M.T., Shanbanovich G.N. (1998) Peculiarities of spring barley development by treating seeds with physiologically active 
substances. Proceedings of the National Academy of Sciences of Belarus. Biological Series [Izvestiya Nacional'noj akademii nauk Belarusi. Seriya biologicheskih nauk], 1: 67-72

Kagale S., Divi U.K., Krochko J.E., Keller W.A., Krishna P. (2007) Brassinosteroid confers tolerance in Arabidopsis thaliana and Brassica napus to a range of abiotic stresses. Planta, 225(2): 353-364

Kang J.G., Yun J., Kim D.H., Chung K.S., Fujioka S., Kim J.I., Dae H.W., Yoshida S., Takatsuto S., Song P.S., Park C.M. (2001) Light and brassinosteroid signals are integrated via a dark-induced small g protein in etiolated seedling growth. Cell, 105(5): 625-636

Kaur S., Bhardwaj R. (2003) Brassinosteroids regulated heavy metals uptake in Brassica campestris L. Annual Meeting of the American Society of Plant Biologists «Plant Biology 2003». Honolulu, p. 628

Khripach V., Zhabinskii V., de Groot A. (2000) Twenty years of brassinosteroids: steroidal plant hormones warrant better crops for the XXI century. Annals of Botany, 86(3): 441-447

Kim B.H., Kim S.Y., Nam K.H. (2012) Genes encoding plant-specific class III peroxidases are responsible for increased cold tolerance of the brassinosteroid-insensitive 1 mutant. Molecules and Cells, 34(6): 539-548

Kim S.Y., Warpeha K.M., Huber S.C. (2019) The brassinosteroid receptor kinase, BRII, plays a role in seed germination and the release of dormancy by cold stratification. Journal of Plant Physiology, 241: UNSP 153031

Kohli S.K., Handa N., Sharma A., Gautam V., Arora S., Bhardwaj R., Alyemeni M.N., Wijaya L., Ahmad P. (2018) Combined effect of 24-epibrassinolide and salicylic acid mitigates lead (Pb) toxicity by modulating various metabolites in Brassica juncea L. seedlings. Protoplasma, 255(1): 11-24

Kopcewicz J. (1971) Influence of steroidal hormones on flower sex expression in Ecballium elaterium (L.). Zeitschrift fur Pflanzenphysiologie, 65: 92-94

Kopcewicz J., Rogozinska J.H. (1972) Effect of estrogens and gibberellic acid on cytokinin and abscisic acid-like compound contents in pea. Experientia, 28(12): 1516-1517

Kopcewicz J., Zatorska Z., Kulikowska H., Szczesniak T. (1977) Endogenous growth-regulators in embryonic shoots of scots pine at time of male and female flower primordia initiation. Acta Societatis Botanicorum Poloniae, 46(1): 119-128

LeGalley E., Widom E., Krekeler M.P.S., Kuentz D.C. (2013) Chemical and lead isotope constraints on sources of metal pollution in street sediment and lichens in southwest Ohio. Applied Geochemistry, 32: $195-203$

Lehman A., Black R., Ecker J.R. (1996) HOOKLESS1, an ethylene response gene, is required for differential cell elongation in the Arabidopsis hypocotyl. Cell, 85(2): 183-194

Li H., Johnson P., Stepanova A., Alonso J.M., Ecker J.R. (2004) Convergence of signaling pathways in the control of differential cell growth in Arabidopsis. Developmental Cell, 7(2): 193-204

Li J. (2010) Regulation of the nuclear activities of brassinosteroid signaling. Current Opinion in Plant Biology, 13(5): 540-547

Li J., Chory J. (1997) A putative leucine-rich repeat receptor kinase involved in brassinosteroid signal transduction. Cell, 90(5): 929-938

Li J., Nam K.H. (2002) Regulation of brassinosteroid signaling by a GSK3/SHAGGY-like kinase. Science, 295(5558): 1299-1301 
Li J., Wen J., Lease K.A., Doke J.T., Tax F.E., Walker J.C. (2002) BAK1, an Arabidopsis LRR receptorlike protein kinase, interacts with BRI1 and modulates brassinosteroid signaling. Cell, 110(2): 213-222

Li L., van Staden J. (1998) Effects of plant growth regulators on the antioxidant system in callus of two maize cultivars subjected to water stress. Plant Growth Regulation, 24(1): 55-66

Li Q.F., He J.X. (2016) BZR1 Interacts with HY5 to mediate brassinosteroid- and light-regulated cotyledon opening in Arabidopsis in darkness. Molecular Plant, 9(1): 113-125

Li X., Zhang Y., Tan M., Liu J., Bao L., Zhang G., Li Y., Iida A. (2009) Atmospheric lead pollution in fine particulate matter in Shanghai, China. Journal of Environmental Sciences, 21(8): 1118-1124

Lima J.V., Lobato A.K.S. (2017) Brassinosteroids improve photosystem II efficiency, gas exchange, antioxidant enzymes and growth of cowpea plants exposed to water deficit. Physiology and Molecular Biology of Plants, 23(1): 59-72

Liu G., Yu Y., Hou J., Xue W., Liu X., Liu Y., Wang W., Alsaedi A., Hayat T., Liu Z. (2014) An ecological risk assessment of heavy metal pollution of the agricultural ecosystem near a lead-acid battery factory. Ecological Indicators, 47: 210-218

Liu W., Zhou Q., Zhang Y., Wei S. (2010) Lead accumulation in different Chinese cabbage cultivars and screening for pollution-safe cultivars. Journal of Environmental Management, 91(3): 781-788

Love A., Love D. (1945) Experiments on the effects of animal sex hormones on dioecious plants. Arkiv for Botanik, 32A: 1-60

Lozano-Duran R., Zipfel C. (2015) Trade-off between growth and immunity: role of brassinosteroids. Trends in Plant Science, 20(1): 12-19

Maret W. (2017) The bioinorganic chemistry of lead in the context of its toxicity. Lead: Its Effects on Environment and Health. Sigel A., Sigel H., Sigel R.K.O. (eds.) Berlin, Walter de Gruyter GmbH \& Co KG, p. 1-20

Miransari M., Smith D.L. (2014) Plant hormones and seed germination. Environmental and Experimental Botany, 99: 110-121

Mora-Garcia S., Vert G., Yin Y., Cano-Delgado A., Cheong H., Chory J. (2004) Nuclear protein phosphatases with Kelch-repeat domains modulate the response to brassinosteroids in Arabidopsis. Genes \& Development, 18(4): 448-460

Muzychenko I., Jamalova G., Mussina U., Kazulis V., Blumberga D. (2017) Case study of lead pollution in the roads of Almaty. Energy Procedia, 113: 369-376

Nakamura A., Higuchi K., Goda H., Fujiwara M.T., Sawa S., Koshiba T., Shimada Y., Yoshida S. (2003) Brassinolide induces IAA5, IAA19, and DR5, a synthetic auxin response element in Arabidopsis, implying a cross talk point of brassinosteroid and auxin signaling. Plant Physiology, 133(4): 1843-1853

Nam K.H., Li J. (2002) BRI1/BAK1, a receptor kinase pair mediating brassinosteroid signaling. Cell, 110(2): 203-212

Nie S., Huang S., Wang S., Mao Y., Liu J., Ma R., Wang X. (2019) Enhanced brassinosteroid signaling intensity via SIBRI1 overexpression negatively regulates drought resistance in a manner opposite of that via exogenous BR application in tomato. Plant Physiology and Biochemistry, 138: 36-47

Noguchi T., Fujioka S., Choe S., Takatsuto S., Tax F.E., Yoshida S., Feldmann K.A. (2000) Biosynthetic pathways of brassinolide in Arabidopsis. Plant Physiology, 124(1): 201-209

Nolan T., Chen J., Yin Y. (2017) Cross-talk of Brassinosteroid signaling in controlling growth and stress responses. Biochemical Journal, 474(16): 2641-2661 
O’Connor D., Hou D., Ye J., Zhang Y., Ok Y.S., Song Y., Coulon F., Peng T., Tian L. (2018) Leadbased paint remains a major public health concern: A critical review of global production, trade, use, exposure, health risk, and implications. Environment International, 121(1): 85-101

Obiora S.C., Chukwu A., Chibuike G., Nwegbu A.N. (2019) Potentially harmful elements and their health implications in cultivable soils and food crops around lead-zinc mines in Ishiagu, Southeastern Nigeria. Journal of Geochemical Exploration, 204: 289-296

Oh M.H., Romanow W.G., Smith R.C., Sasse J., Clouse S.D. (1996) BRU1 encodes a xyloglucan endo-transglycosylase that is expressed in inner and outer tissues of elongating soybean epicotyls. Plant Physiology, 111(2): 482-482

Oh M.H., Romanow W.G., Smith R.C., Zamski E., Sasse J., Clouse S.D. (1998) Soybean BRU1 encodes a functional xyloglucan endotransglycosylase that is highly expressed in inner epicotyl tissues during brassinosteroid-promoted elongation. Plant and Cell Physiology, 39(1): 124-130

Park K.H., Park J.D., Hyun K.H., Nakayama M., Yokota T. (1994) Brassinosteroids and monoglycerides with brassinosteroid-like activity in immature seeds of Oryza sativa and Perilla frutescens and in cultured cells of Nicotiana tabacum. Bioscience, Biotechnology, and Biochemistry, 58(12): 2241-2243

Parmoon G., Ebadi A., Jahanbakhsh S., Hashemi M. (2019) Physiological response of fennel (Foeniculumvulgare Mill.) to drought stress and plant growth regulators. Russian Journal of Plant Physiology, 66(5): 795-805

Planas-Riverola A., Gupta A., Betegon-Putze I., Bosch N., Ibanes M., Cano-Delgado A.I. (2019) Brassinosteroid signaling in plant development and adaptation to stress. Development, 146(5): UNSP dev151894

Pociecha E., Jurczyk B., Dziurka M., Paczyński R., Okleštková J., Janeczko A. (2015) 24-Epibrassinolide promotes carbohydrates accumulation in crowns of perennial ryegrass during cold acclimation by regulation of gene expression and enzyme activities which results in increased frost tolerance. Procedia Environmental Sciences, 29: 234-235

Pourrut B., Jean S., Silvestre J., Pinelli E. (2011) Lead-induced DNA damage in Vicia faba root cells: Potential involvement of oxidative stress. Mutation Research. Genetic Toxicology and Environmental Mutagenesis, 726(2): 123-128

Pragst F., Stieglitz K., Runge H., Runow K.D., Quig D., Osborne R., Runge C., Ariki J. (2017) High concentrations of lead and barium in hair of the rural population caused by water pollution in the Thar Jath oilfields in South Sudan. Forensic Science International, 274: 99-106

Pugachov R.M., Matveew V.A., Skorina V.V. (2000) Influence of mineral and hormonal composition of nutrient medium on prune, cherry plum and sloe embryos germination and growing in vitro. Sodininkystè ir Daržininkystè, 19(3): 454-463

Rao S.S.R., Raghu K. (2017) Effect of 24-epibrassinolide on growth and metabolism of rosescented geranium [Pelargonium graveolens (L.) Herit] under cadmium toxicity. International Journal of Botany Studies, 2(4): 54-59

Raz V., Ecker J.R. (1999) Regulation of differential growth in the apical hook of Arabidopsis. Development, 126(16): 3661-3668

Reichmayr-Lais A.M., Kurchgessner M. (1984) Lead. Biochemistry of the essential ultratrace elements. Frieden E. (ed.) New York - London, Plenum Press, p. 367-387 
Rout G.R., Das P. (2003) Effect of metal toxicity on plant growth and metabolism: I. Zinc. Agronomie, 23(1): 3-11

Saibo N.J.M., Vriezen W.H., Beemster G.T.S., Van Der Straeten D. (2003) Growth and stomata development of Arabidopsis hypocotyls are controlled by gibberellins and modulated by ethylene and auxins. Plant Journal, 33(6): 989-1000

Sairam R.K. (1994) Effects of homobrassinolide application on plant metabolism and grain yield under irrigated and moisture-stress conditions of two wheat varieties. Plant Growth Regulation, 14(2): 173-181

Sakurai A., Yokota T., Clouse S.D. (1999) Brassinosteroids: steroidal plant hormones. Tokyo, Springer, $264 \mathrm{p}$.

Sasse J. (1999) Physiological actions of brassinosteroids. Brassinosteroids: steroidal plant hormones. Sakurai A., Yokota T., Clouse S.D. (eds.) Tokyo, Springer, p. 137-161

Schneider J.A., Yoshihara K., Nakanishi K., Kato N. (1983) Typhasterol (2-deoxycastasterone) - a new plant-growth regulator from cat-tail pollen. Tetrahedron Letters, 24(36): 3859-3860

Schwark A., Schierle J. (1992) Interaction of ethylene and auxin in the regulation of hook growth I: the role of auxin in different growing regions of the hypocotyl hook of Phaseolus vulgaris. Journal of Plant Physiology, 140(5): 562-570

Serna M., Hernández F., Coll F., Amorós A. (2012) Brassinosteroid analogues effect on yield and quality parameters of field-grown lettuce (Lactuca sativa L.). Scientia Horticulturae, 143: 29-37

Sharma A., Thakur S., Kumar V., Kanwar M.K., Kesavan A.K., Thukral A.K., Bhardwaj R., Alam P., Ahmad P. (2016a) Pre-sowing seed treatment with 24-epibrassinolide ameliorates pesticide stress in Brassica juncea L. through the modulation of stress markers. Frontiers in Plant Science, 7: 1569

Sharma I., Bhardwaj R., Pati P.K. (2015) Exogenous application of 28-homobrassinolide modulates the dynamics of salt and pesticides induced stress responses in an elite rice variety Pusa Basmati-1. Journal of Plant Growth Regulation, 34(3): 509-518

Sharma M., Mahajan P., Singh H.P., Batish D.R., Kohli R.K. (2019) 24-Epibrassinolide pretreatment reduces alkaline-induced oxidative stress in red rice seedlings. Environmental Science and Pollution Research, 26(22): 23192-23197

Sharma P., Bhardwaj R. (2007) Effects of 24-epibrassinolide on growth and metal uptake in Brassica juncea L. under copper metal stress. Acta Physiologiae Plantarum, 29(3): 259-263

Sharma P., Kumar A., Bhardwaj R. (2016b) Plant steroidal hormone epibrassinolide regulate Heavy metal stress tolerance in Oryza sativa L. by modulating antioxidant defense expression. Environmental and Experimental Botany, 122: 1-9

She J., Han Z., Kim T.-W., Wang J., Cheng W., Chang J., Shi S., Wang J., Yang M., Wang Z.-Y., Chai J. (2011) Structural insight into brassinosteroid perception by BRI1. Nature, 474(7352): 472-476

Shigeta T., Zaizen Y., Sugimoto Y., Nakamura Y., Matsuo T., Okamoto S. (2015) Heat shock protein 90 acts in brassinosteroid signaling through interaction with BES1/BZR1 transcription factor. Journal of Plant Physiology, 178: 69-73

Shimada Y., Goda H., Nakamura A., Takatsuto S., Fujioka S., Yoshida S. (2003) Organ-specific expression of brassinosteroid-biosynthetic genes and distribution of endogenous brassinosteroids in Arabidopsis. Plant Physiology, 131(1): 287-297 
Sihlahla M., Mouri H., Nomngongo P.N. (2019) Uptake of trace elements by vegetable plants grown on agricultural soils: Evaluation of trace metal accumulation and potential health risk. Journal of African Earth Sciences, 160: 103635

Silk W.K., Erickson R.O. (1978) Kinematics of hypocotyl curvature. American Journal of Botany, 65(3): 310-319

Singh A.P., Savaldi-Goldstein S. (2015) Growth control: brassinosteroid activity gets context. Journal of Experimental Botany, 66(4): 1123-1132

Skarzynski B. (1933) An estrogenic substance from plant material. Nature, 131: 766

Skerfving S., Bergdahl I.A. (2015) Chapter 43 - lead. Handbook on the toxicology of metals. Volume II: Specific metals. Nordberg G.F., Fowler B.A., Nordberg M. (eds.) Cambridge, Massachusetts, Academic Press, p. 911-967

Small C.C., Degenhardt D. (2018) Plant growth regulators for enhancing revegetation success in reclamation: A review. Ecological Engineering, 118: 43-51

Small C.C., Degenhardt D., McDonald T. (2019) Plant growth regulators for enhancing Alberta native grass and forb seed germination. Ecological Engineering: X, 1: 100003

Smalle J., Haegman M., Kurepa J., Van Montagu M., Van Der Straeten D. (1997) Ethylene can stimulate Arabidopsis hypocotyl elongation in the light. Proceedings of the National Academy of Sciences of the United States of America, 94(6): 2756-2761

Sonjaroon W., Jutamanee K., Khamsuk O., Thussagunpanit J., Kaveeta L., Suksamrarn A. (2018) Impact of brassinosteroid mimic on photosynthesis, carbohydrate content and rice seed set at reproductive stage under heat stress. Agriculture and Natural Resources, 52(3): 234-240

Stepanova A.N., Robertson-Hoyt J., Yun J., Benavente L.M., Xie D.Y., Dolezal K., Schlereth A., Jürgens G., Alonso J.M. (2008) TAA1-mediated auxin biosynthesis is essential for hormone crosstalk and plant development. Cell, 133(1): 177-191

Stevens T., Forgas M. (1997) Structure, function and regulation of the vacuolar H+-ATPase. Annual Review of Cell and Developmental Biology, 13: 779-808

Surgun-Acar Y., Zemheri-Navruz F. (2019) 24-Epibrassinolide promotes arsenic tolerance in Arabidopsis thaliana L. by altering stress responses at biochemical and molecular level. Journal of Plant Physiology, 238: 12-19

Symons G.M., Reid J.B. (2004) Brassinosteroids do not undergo long-distance transport in pea. Implications for the regulation of endogenous brassinosteroid levels. Plant Physiology, 135(4): 2196-2206

Tang W., Kim T.-W., Oses-Prieto J.A., Sun Y., Deng Z., Zhu S., Wang R., Burlingame A.L., Wang Z.-Y. (2008) BSKs mediate signal transduction from the receptor kinase BRII in Arabidopsis. Science, 321(5888): 557-560

Toyama S. (2000) Recent studies on brassinosteroids - With special regard to the growth physiology of crop plants. Japanese Journal of Crop Science, 69(4): 453-463

Tran L.S., Pal S. (2014) Phytohormones: a window to metabolism, signaling and biotechnological applications. New York, Springer-Verlag, $361 \mathrm{p}$.

Tunc-Ozdemir M., Jones A.M. (2017) BRL3 and AtRGS1 cooperate to fine tune growth inhibition and ROS activation. PLOS ONE, 12(5): e0177400

Vandenbussche F., Petrasek J., Zadnikova P., Hoyerova K., Pesek B., Raz V., Swarup R., Bennett M., Zazimalova E., Benkova E., Van Der Straeten D. (2010) The auxin influx carriers AUX1 and LAX3 
are involved in auxin-ethylene interactions during apical hook development in Arabidopsis thaliana seedlings. Development, 137(4): 597-606

Vandenbussche F., Smalle J., Le J., Saibo N.J.M., De Paepe A., Chaerle L., Tietz O., Smets R., Laarhoven L.J.J., Harren F.J.M., Van Onckelen H., Palme K., Verbelen J.-P., Van Der Straeten D. (2003a) The Arabidopsis mutant alh1 illustrates a cross talk between ethylene and auxin. Plant Physiology, 131(3): 1228-1238

Vandenbussche F., Van Der Straeten D. (2004) Shaping the shoot: a circuitry that integrates multiple signals. Trends in Plant Science, 9(10): 499-506

Vandenbussche F., Vriezen W.H., Smalle J., Laarhoven L.J.J., Harren F.J.M., Van Der Straeten D. (2003b) Ethylene and auxin control the Arabidopsis response to decreased light intensity. Plant Physiology, 133(2): 517-527

Venugopal B., Luckey T.D. (1978) Metal toxicity in mammals: Chemical toxicity of metals and metalloids. New York, London, Plenum Press, 409 p.

Verma V., Ravindran P., Kumar P.P. (2016) Plant hormone-mediated regulation of stress responses. BMC Plant Biology, 16: 86

Vert G., Nemhauser J.L., Geldner N., Hong F., Chory J. (2005) Molecular mechanisms of steroid hormone signaling in plants. Annual Review of Cell and Developmental Biology, 21: $177-201$

Vriezen W.H., Achard P., Harberd N.P., Van Der Straeten D. (2004) Ethylene-mediated enhancement of apical hook formation in etiolated Arabidopsis thaliana seedlings is gibberellin dependent. Plant Journal, 37(4): 505-516

Vukasinovic N., Russinova E. (2018) BRexit: possible brassinosteroid export and transport routes. Trends in Plant Science, 23(4): 285-292

Wang F.J., Zhang Y.T., Guo Q.X., Tan H.F., Han J.H., Lin H.R., Wei H.W., Xu G.W., Zhu C. (2018) Effects of exogenous 5-aminolevulinic acid and 24-epibrassinolide on $\mathrm{Cd}$ accumulation in rice from Cd-contaminated soil. Rice Science, 25(6): 320-329

Wang X., Chory J. (2006) Brassinosteroids regulate dissociation of BKII, a negative regulator of BRI1 signaling, from the plasma membrane. Science, 313(5790): 1118-1122

Wang Y.T., Chen Z.Y., Jiang Y., Duan B.B., Xi Z.M. (2019) Involvement of ABA and antioxidant system in brassinosteroid-induced water stress tolerance of grapevine (Vitis vinifera L.). Scientia Horticulturae, 256: 108596

Wang Z.Y., Bai M.Y., Oh E., Zhu J.Y. (2012) Brassinosteroid signaling network and regulation of photomorphogenesis. Annual Review of Genetics, 46: 701-724

Wang, H., Yang C., Zhang C., Wang N., Lu D., Wang J., Zhang S., Wang Z.-X., Ma H., Wang X. (2011) Dual role of BKI1 and 14-3-3 s in brassinosteroid signaling to link receptor with transcription factors. Developmental Cell, 21(5): 825-834

Watt M.P., Cresswell C.F. (1987) A comparison between the utilization of storage protein and exogenous nitrate during seedling establishment in Zea mays L. Plant, Cell and Environment, 10(4): $327-332$

Wu C.C., Li F., Xu H., Zeng W.M., Yu R.L., Wu X.L., Shen L., Liu Y.D., Li J.K. (2019) The potential role of brassinosteroids (BRs) in alleviating antimony (Sb) stress in Arabidopsis thaliana. Plant Physiology and Biochemistry, 141: 51-59 
Xia X.-J., Huang L.-F., Zhou Y.-H., Mao W.-H., Shi K., Wu J.-X., Asami T., Chen Z., Yu J.-Q. (2009) Brassinosteroids promote photosynthesis and growth by enhancing activation of Rubisco and expression of photosynthetic genes in Cucumis sativus. Planta, 230(6): 1185-1196

Xu R.J., Guo Y.S., Zhao Y.J. (1990) Epibrassinolide-induced changes in the elongation, endogenous GA_3, ABA and starch content of cucumber hypocotyls. Acta Photophysiologica Sinica, 2: 27-29 (in Chinese, Summary in English)

Yamagami A., Chieko S., Sakuta M., Shinozaki K., Osada H., Nakano A., Asami T., Nakano T. (2018) Brassinosteroids regulate vacuolar morphology in root meristem cells of Arabidopsis thaliana. Plant Signaling \& Behavior, 13(4): e1417722

Yamamoto R., Fujioka S., Iwamoto K., Demura T., Takatsuto S., Yoshida S., Fukuda H. (2007) Co-regulation of brassinosteroid biosynthesis-related genes during xylem cell differentiation. Plant and Cell Physiology, 48(1): 74-83

Yan Z., Zhao J., Peng P., Chihara R.K., Li J. (2009) BIN2 functions redundantly with other Arabidopsis GSK3-like kinases to regulate brassinosteroid signaling. Plant Physiology, 150(2): 710721

Ye H., Liu S., Tang B., Chen J., Xie Z., Nolan T.M., Jiang H., Guo H., Lin H.-Y., Li L., Wang Y., Tong H., Zhang M., Chu C., Li Z., Aluru M., Aluru S., Schnable P.S., Yin Y. (2017) RD26 mediates crosstalk between drought and brassinosteroid signalling pathways. Nature Communications, 8(1): 14573

Yin W.C., Dong N.N., Niu M., Zhang X.X., Li L.L., Liu J., Liu B., Tong H.N. (2019) Brassinosteroidregulated plant growth and development and gene expression in soybean. Crop Journal, 7(3): 411-418

Yokota T., Arima M., Takahashi N. (1982) Castasterone, a new phytosterol with plant-hormone potency from chestnut insect gall. Tetrahedron Letters, 23(12): 1275-1278

Yokota T., Ohnishi T., Shibata K., Asahina M., Nomura T., Fujita T., Ishizaki K., Kohchi T. (2017) Occurrence of brassinosteroids in non-flowering land plants, liverwort, moss, lycophyte and fern. Phytochemistry, 136: 46-55

Yoshida T., Mogami J., Yamaguchi-Shinozaki K. (2014) ABA-dependent and ABA-independent signaling in response to osmotic stress in plants. Current Opinion in Plant Biology, 21: 133-139

Yuan G.F., Jia C.G., Li Z., Sun B., Zhang L.P., Liu N., Wang Q.M. (2010) Effect of brassinosteroids on drought resistance and abscisic acid concentration in tomato under water stress. Scientia Horticulturae, 126(2): 103-108

Zadnikova P., Petrasek J., Marhavy P., Raz V., Vandenbussche F., Ding Z., Schwarzerová K., Morita M.T., Tasaka M., Hejátko J., Van Der Straeten D., Friml J., Benková E. (2010) Role of PINmediated auxin efflux in apical hook development of Arabidopsis thaliana. Development, 137(4): 607-617

Zhang H., Wei K., Zhang M., Liu R., Chen Y. (2014) Assessing the mechanism of DNA damage induced by lead through direct and indirect interactions. Journal of Photochemistry and Photobiology. B: Biology, 136: 46-53

Zhao B., Li J. (2012) Regulation of brassinosteroid biosynthesis and inactivation. Journal of Integrative Plant Biology, 54(10): 746-759

Zhao Y., Christensen S.K., Fankhauser C., Cashman J.R., Cohen J.D., Weigel D., Chory J. (2001) A role for flavin monooxygenase-like enzymes in auxin biosynthesis. Science, 291(5502): 306-309 
Zheng Y.X., Xu B., Ren K.L., Zhang Y.P., Wu J.C. (2017) Impact of soil drench and foliar spray of 24-epibrassinolide on the growth, yield, and quality of field-grown Moringa oleifera in Southwest China. Journal of Plant Growth Regulation, 36(4): 931-941

Zhou Y.L., Huo S.F., Wang L.T., Meng J.F., Zhang Z.W., Xi Z.M. (2018) Exogenous 24-epibrassinolide alleviates oxidative damage from copper stress in grape (Vitis vinifera $\mathrm{L}$.) cuttings. Plant Physiology and Biochemistry, 130: 555-565

Zhu J.-Y., Sae-Seaw J., Wang Z.-Y. (2013) Brassinosteroid signalling. Development, 140(8): 16151620

Zhu Y., Wang B., Tang K., Hsu C.-C., Xie S., Du H., Yang Y., Tao W.A., Zhu J.-K. (2017) An Arabidopsis Nucleoporin NUP85 modulates plant responses to ABA and salt stress. PLOS Genetics, 13(12): e1007124

Zhu Z.G., Liang H.L., Chen G.P., Tang B.Y., Tian S.B., Hu Z.L. (2019) Isolation of the brassinosteroid receptor genes and recharacterization of dwarf plants by silencing of SIBRI1 in tomato. Plant Growth Regulation, 89(1): 59-71

Zou L.-J., Deng X.-G., Zhang L.-E., Zhu T., Tan W.-R., Muhammad A., Zhu L.-J., Zhang C., Zhang D.-W., Lin H.-H. (2018) Nitric oxide as a signaling molecule in brassinosteroid-mediated virus resistance to Cucumber mosaic virus in Arabidopsis thaliana. Physiologia Plantarum, 163(2): 196-210

Zwarich M.A., Mills J.G. (1982) Heavy metal accumulation by some vegetable crops grown on sewage-sludge-amended soils. Canadian Journal of Soil Science, 62(2): 243-247 